\title{
'Preparation and characterization of a novel mucoadhesive carvedilol nano-sponge: a promising platform for buccal antihypertensive delivery'
}

Nahed Mohamed Sallam

NODCAR: National Organization for Drug Control and Research

Rania Abdel-Basset Sanad ( $\nabla$ sanadrani3@yahoo.com )

National Organization for Drug Control and Research https://orcid.org/0000-0003-3992-174X

Mahgoub Mohamed Ahmed

NODCAR: National Organization for Drug Control and Research

EL Sayed Abdu Khafagy

Suez Canal University Faculty of Pharmacy

Mamdouh Mostafa Ghorab

Suez Canal University Faculty of Pharmacy

Shadeed Gad

Suez Canal University Faculty of Pharmacy

\section{Research Article}

Keywords: Bilosomes, buccal mucosa, carvedilol, heart biomarkers, mucoadhesive-sponge, oxidative stress biomarkers

Posted Date: March 5th, 2021

DOl: https://doi.org/10.21203/rs.3.rs-268464/v1

License: (9) This work is licensed under a Creative Commons Attribution 4.0 International License. Read Full License 
Title:

'Preparation and characterization of a novel mucoadhesive carvedilol nano-sponge: a promising platform for buccal antihypertensive delivery'

Nahed Mohamed Sallam ${ }^{1}$, Rania Abdel-Basset Sanad ${ }^{1, *}$, Mahgoub Mohamed Ahmed², EL Sayed Abdu Khafagy ${ }^{3}$, Mamdouh Mostafa Ghorab³and Shadeed Gad ${ }^{3}$.

${ }^{1}$ Department of Pharmaceutics, National Organization for Drug Control and Research, Egypt

${ }^{2}$ Department of Molecular Drug Evaluation, National Organization for Drug Control and Research, Egypt

${ }^{3}$ Department of Pharmaceutics, Faculty of Pharmacy, Suez Canal University.

* The corresponding author:

Rania Abdel-Basset Sanad, Ph.D.

Associate Professor-Department of Pharmaceutics, National Organization of Drug Control and Research (NODCAR), Giza, Egypt.

E-mail address: sanadrania3@yahoo.com;

Phone number: +002 01224980700;

ORCID ID: 0000-0003-3992-174X

Postal Address: Department of Pharmaceutics, National Organization of Drug Control and Research (NODCAR), 6 Abou Hazem Street, Pyramids Ave., Giza, Egypt. 


\section{Abstract}

Purpose: Carvedilol (CRV) is a non-selective beta-blocker used for hypertension treatment, angina pectoris, and heart failure. Oral administration of CRV showed poor bioavailability (25\%), which may be due to exposure to the first-pass metabolism. Buccal delivery was used to boost its bioavailability.

Methods: In this study carboxymethylcellulose/hydroxypropyl cellulose (CMC/HPC) composite buccal sponge enriched with CRV bilosomes was developed. Bilosomes were prepared using the thin-film hydration-sonication technique by applying a $3^{2}$ factorial design.

Results: BL9 possessed the highest desirability value $(0.861)$ and therefore, it was chosen as an optimal bilosomes. It exhibited a spherical shape with $217.2 \mathrm{~nm}, 87.13 \%$ entrapment efficiency, and a sustained release of CRV up to $24 \mathrm{~h}$. Consecutively, BL9 was incorporated in a CMC/HPC gel and lyophilized for $24 \mathrm{~h}$ to obtain a CMC-HPCL9 bilosomal sponge to enhance CRV buccal delivery. Morphological analysis of the prepared sponge with improved swelling showed a porosity of 67.58 percent. The in vivo assessment of rats indicates that the CMCHPC/BL9 sponge enhances systolic/diastolic blood pressure, lipid profiles, oxidative stress biomarkers, and heart biomarkers with improved heart tissue quality.

Conclusion: These results strongly encourage the use of this novel CMC-HPC/BL9 composite buccal sponge for the management of hypertension.

Keywords: Bilosomes; buccal mucosa; carvedilol; heart biomarkers; mucoadhesive-sponge; oxidative stress biomarkers. 


\section{Introduction:}

Carvedilol (CRV) is a non-selective beta-blocker used for hypertension treatment, angina pectoris, and heart failure. It is practically insoluble with a solubility value of $4.4 \mu \mathrm{g} / \mathrm{mL}$ in water and it has a weak basic character (pKa value 6.8)[1]. Because of its low solubilities and exposure to first passe metabolism, oral administration of CRV showed very low bioavailability (25\%) [2].

Recently, various nano-systems, have been used to improve the solubility, bioavailability, and stability of lipophilic drugs through lipid-based formulations [3]. Among these nano-systems, liposomes showed a great promising drug delivery by enhancing their distribution, thus enhancing their efficacy and/or reducing their toxicity. liposomes (LPS) can entrap both lipophilic and hydrophilic drugs [4]. However, drug leakage and storage instability are identified as the primary disadvantages of liposomal carriers. The presence of bile salts increases the stability of liposomes [5]. So, encapsulation of lipophilic drug in a bile salt liposome (bilosome) platform followed by incorporation into a buccal mucoadhesive dosage form would overcome the fore mentioned problems [4].

The buccal cavity has been tested as an alternative to the oral route as a site for drug administration [6]. Literature reported different buccal liposomal dosage forms including silymarin liposomes [7], buccal deformable insulin liposomes [8].

More outstandingly, the incorporation of bilosomes in sponge can combine the advantages of both platforms and thus opens the door to more enhanced buccal drug delivery with unique advances such as improved localization in the buccal mucosa, minimized burst release, and controlled drug release [9] [10].

The sponge is a polymeric dispersion lyophilized to give a porous solid structure [10]. Attempts for extended and enhanced drug contact with the mucosa have led to the development of mucoadhesive sponges [4]. This could be achieved by using mucoadhesive polymers [9]. Cellulose derivatives are the most used polymers. Carboxymethyl cellulose (CMC) is a wellknown polysaccharide-mucoadhesive, water-soluble, ionizable polymer in which $-\mathrm{CH} 2 \mathrm{COOH}$ groups are substituted on the glucose units of the cellulose chain [11]. Hydroxypropyl cellulose is also a cellulose derivative, available at low cost and wide range of molecular weights, soluble in water and most organic solvents. It has thickening and stabilizing properties making it an attractive biomaterial [12].

Yet, there is no published work that used CRV in a bilosomal sponge. The novelty of this work is to exploit the lucid biocompatibility and biodegradability of CMC-HPC sponge loaded with CRV bilosomes (CRV BL-SP) as an innovative antihypertensive dosage form. Consequently, this 
in vitro and in vivo study aimed to evaluate the antihypertensive efficiency of CMC-HPC sponge enriched with CRV- BLS. The in-vivo study was done by the pharmacodynamic evaluation of certain biochemical parameters as lipid profile (cholesterol, triglycerides, LDL, and $\mathrm{HDL}$ ), oxidative stress parameters (ROS, NO, TAC) in the heart to assess the efficacy of this innovative formula to improve cardiac functions compared to $\mathrm{CdCL}_{2}$ and $\mathrm{Carvid}^{\odot}$.

\section{Materials and methods}

\subsection{Materials}

Carvedilol (CRV), SAGA Pharmaceutical Co. (6 Th $^{\text {th }}$ October, Egypt). Soya bean phosphatidylcholine (SPC), cholesterol $(\mathrm{CH})$, sodium deoxycholate $(\mathrm{SDC})$, dialysis membrane (12,000-14,000 molecular weight cut-off), Griess reagent, and thiobarbituric acid, Sigma (Missouri, USA). Carboxymethylcellulose, Hydroxypropyl cellulose, Fluka Co. All other chemicals and reagents used were of analytical grade.

\subsection{Methods}

\subsubsection{Preparation of bilosomes (BLS)}

CRV loaded BLS were prepared by thin-film hydration-sonication technique [16]. Briefly, the required amount of phosphatidylcholine, cholesterol, diacetylphosphate, and CRV was completely dissolved in $5 \mathrm{ml}$ dichloromethane. The resultant lipid solution was then evaporated at $60^{\circ} \mathrm{C}$ in a rotavap (Rota-Vap, Buchi, Germany) under reduced pressure to produce a film of lipids. The lipid film was then hydrated using $25 \mathrm{ml}$ distilled water containing $25 \mathrm{mg}$ sodium deoxycholate (SDC) and sonicated for $5 \mathrm{~min}$ at $60^{\circ} \mathrm{C}$ (Sonicator, Crest Ultra Sonicator Model 575DAE, Trenton, NJ). The BLS dispersions were obtained and then stored in a refrigerator at $5^{\circ} \mathrm{C}$ till further investigations. The composition of the prepared bilosomes is given in Table 1.

\subsubsection{Experimental design}

Full-factorial design $3^{2}$ was used to study the influence of the independent variables namely: lipid concentration (X1) and cholesterol concentration (X2) on the dependent variables shown in Table 2. Design-Expert ${ }^{\otimes 7}$ Soft-ware (Stat-Ease Inc., USA) was used to conduct a statistical study of responses. 


\subsection{In-vitro characterization of BLS formulations}

\subsubsection{Determination of particle size}

A laser scattering particle size analyzer (Malvern Instrument Ltd., Worcestershire, UK) was used to determine particle size, polydispersity index, and zeta potential of the bilosomes.

\subsubsection{Entrapment efficiency (EE \%) and drug loading (DL)}

CRV entrapped in BLS dispersions was separated from the un-entrapped drug by centrifugation of the dispersion for $0.5 \mathrm{~h}$ at $4^{\circ} \mathrm{C}$ using a cooling centrifuge (Beckman, Fullerton, Canada). The supernatants were then analyzed for CRV content. EE and DL were computed by the following equations [13].

$$
\begin{aligned}
E E \% & =\frac{(\mathrm{Di}-\mathrm{Dn})}{\mathrm{Di} \times 100} \\
\mathrm{DL} & =\frac{(\mathrm{Di}-\mathrm{Dn})}{\mathrm{L} \times 100}
\end{aligned}
$$

Where Di: initial drug amount, Dn: unentrapped drug, and L: total lipid.

\subsubsection{In vitro drug release study}

Release of CRV-BLS or drug suspension equivalent to $6.25 \mathrm{mg}$ drug were determined using the dialysis bag method [14]. The bags were placed in $250 \mathrm{~mL}$ PBS, pH 6.8 containing $0.5 \%$ sodium lauryl sulfate (SLS), at $37^{\circ} \mathrm{C}$ and stirred at $50 \mathrm{rpm}$ for $24 \mathrm{~h}$. Samples were withdrawn at 1, 2, 3, $4,5,6,8,12$ and $24 \mathrm{~h}$ and then CRV\% was determined spectrophotometrically at $242 \mathrm{~nm}$ and computed by equation 3 .

$$
\% \mathrm{CRV} \text { released }=\frac{\mathrm{Mt}}{\mathrm{Mi} \mathrm{X} 100}
$$

Where $\mathrm{Mi}$ is the initial amount of the CRV in BLS and $\mathrm{Mt}$ is the amount of drug released at time t.

The release of the free drug suspension $(6.25 \mathrm{mg})$ was also investigated in the same way. Triplicate experiments were carried out and the findings are shown as mean \pm S.D.

The results obtained from the release studies were kinetically analyzed for the order of drug release. The different formulae were fitted to Zero-order, first order, and the Higuchi diffusion models, and the correlation coefficient values $\left(R^{2}\right)$ were determined.

\subsubsection{Ex-vivo permeation}


The permeation of CRV-BLS was investigated using the sheep buccal mucosa to detect the ability of BLS for enhancing drug permeation in vivo. The results were compared with the CRV permeation rate and extent from CRV suspension in a buffer. The buccal mucosa was thawed, fixed at one end of a glass cylinder and the other end of the cylinder was connected to the shafts of dissolution apparatus I. All other conditions of the test were as previously employed in the in vitro dissolution test. CRV-BLS volume equivalent to $6.25 \mathrm{mg}$ drug, was placed in the glass cylinders. Samples of $3 \mathrm{ml}$ were withdrawn from the permeation medium at the specified time intervals: $0.5,1,2,3,4,6,8,12$, and $24 \mathrm{~h}$, followed by compensation with equal volumes of fresh medium. The amount of drug permeated was analyzed using a UV spectrophotometer (Shimadzu, Tokyo, Japan) at $242 \mathrm{~nm}$. The accumulated quantity of CRV per unit area was graphically displayed as a function time $\left(\mu \mathrm{g} / \mathrm{cm}^{2}\right)$, and the permeation parameters could be determined. The flux of CRV from control suspension or BLS at $24 \mathrm{~h}$ (Jmax) and enhancement ratio(ER) was calculated according to the following equations [4]:

$$
\begin{aligned}
\text { Jmax } & =\frac{\text { Amount of drug permeated per unit area }}{\text { Time }} \\
\mathrm{ER} & =\frac{\text { Jmax bilosomal formula }}{\text { Jmax of control (CRV susp) }}
\end{aligned}
$$

Besides, the permeability coefficient $\mathrm{Kp}(\mathrm{cm} / \mathrm{h})$ of CRV from BLS can be calculated by dividing the slope of the curve by initial drug concentration.

One-way ANOVA was utilized to statistically evaluate the differences in Imax values and total amount permeated of the drug from BLS using SPSS 18.0 software ${ }^{\circledR}$.

\subsubsection{Selection of the optimized formulation of the BLS}

Design Expert ${ }^{\circledR}$ software (Version 7, Stat-Ease Inc., MN, USA) was utilized to optimize BLS formulations. The optimum formula that has the highest EE\%, CRV cumulative \% released after $24 \mathrm{~h}$ with lower PS and PDI. Desirability values were calculated. The formula obtained with the highest desirability value was considered as the optimum formula.

\subsection{Confocal laser scanning microscopy (CLSM) study}

CLSM was used to study the depth of penetration of the optimized bilosomes into the sheep buccal mucosa. Rhodamine B solution and optimum BLS formula loaded with rhodamine B were applied to sheep buccal mucosa, followed by its removal, and washing with distilled water. The applied area was frozen at $-20^{\circ} \mathrm{C}$, then was sectioned with a cryostat into $20 \mu \mathrm{m}$ slices and put-on slides and covered by glass coverslips. The slides were then microscopically inspected using an inverted laser scanning confocal microscope LSM 710 (CRVI Zeiss, 
Germany) without any extra processing. The rhodamine energized with a $\mathrm{He} / \mathrm{Ne}$ laser was at $524 \mathrm{~nm}$ and light emission was at $580 \mathrm{~nm}$ [15].

\subsection{Differential scanning calorimetry (DSC) of BLS}

DSC thermograms of CRV pure powder, SPC, cholesterol, sodium deoxycholate, and the optimized lyophilized CRV BLS formulation were recognized using Shimadzu differential scanning calorimeter (DSC-50, Kyoto, Japan). About $2 \mathrm{mg}$ of each sample was subjected to heat in a range of 10 to $300^{\circ} \mathrm{C}$ at a constant heating rate of $10^{\circ} \mathrm{C} / \mathrm{min}$ in a standard aluminum pot under an inert nitrogen flow of $25 \mathrm{ml} / \mathrm{min}$.

\subsection{Transmission Electron Microscope (TEM)}

The morphology of the optimized CRV BLS was detected by TEM (Joel JEM 1230, Tokyo, Japan). It was dried on a carbon-coated copper, stained with phosphotungstic acid, and visualized at $200 \mathrm{kV}$.

\subsection{Stability studies for bilosomes (BLS)}

The optimized CRV-loaded bilosomes preparation was stored at a temperature of $4 \pm 2{ }^{\circ} \mathrm{C}$ for 3 months. Physical stability was evaluated by comparing the results of EE\% and PS studies before and after storage time [16].

Results obtained were analyzed statistically using SPSS $18.0^{\circledR}$ (SPSS Inc., Chicago, IL, United States) using Student's- t-test. The difference was considered significant at $p \leq 0.05$.

\subsection{Preparation of CMC-HPC /CRV-BLS sponge}

CMC-HPC sponge enriched with CRV- BLS was prepared in two steps. First, CMC-HPC blend $(2 \% \mathrm{w} / \mathrm{v})$ was prepared by mixing polymeric blend solution ( $2 \% \mathrm{w} / \mathrm{v} C \mathrm{CMC}$ and HPC at ratio $1: 1)$ dissolved in distilled water with the optimized BLS dispersion at a ratio of 1:1 and stirred, poured into a silicone mold, frozen and lyophilized for $24 \mathrm{~h}$.

\subsection{Characterization of CMC-HPC /CRV-BLS sponge}

\subsubsection{Sponge $\mathrm{pH}$}

The surface $\mathrm{pH}$ of the sponge was determined by putting it to swell in contact with $2 \mathrm{ml}$ simulated saliva fluid ( $\mathrm{pH} 6.8$ ) for $2 \mathrm{~h}$ at room temperature. This followed by, bringing the 
electrode of the $\mathrm{pH}$-meter (Jenway 3510, Barloworld Scientific, UK) in contact with the sponge surface and left to equilibrate for $1 \mathrm{~min}$ [17].

\subsubsection{Ex Vivo Mucoadhesion Time}

The internal side of a beaker was attached to a sheep buccal mucosa. A $50 \mu \mathrm{l}$ of simulated saliva was moistened with the sponge, which was fixed to the buccal mucosa after applying a slight force. The beaker contained SSF at $37 \pm 1^{\circ} \mathrm{C}$; a stirring rate of $50 \mathrm{rpm}$ was applied. Mucoadhesive time was recorded when a complete detachment of the sponge occurred [17].

\subsubsection{Porosity determination}

Samples of known volume (V) and weight (Wi) were immersed in a graduated cylinder containing ethanol and soaked for $24 \mathrm{~h}$ [18]. The final wet sponge weight was recorded as Wf. Porosity \% was calculated:

Porosity $\%=\left(\frac{\mathrm{Wf}-\mathrm{Wi}}{\rho \text { ethanol }} \div \mathrm{V}\right) \times 100$

Where $\rho$ ethanol: Density of ethanol

\subsubsection{Swelling ratio}

The sponge was immersed in PBS for different time points and incubated at $37^{\circ} \mathrm{C}$. The swelling ratio was estimated [10]:

Swelling ratio $=\frac{\mathrm{Ww}-\mathrm{Wi}}{\mathrm{Wi}}$

Where $\mathrm{Wi}$ is the sponge's initial weight and $\mathrm{WW}$ is the sponge's weight after hydration and removing the excess buffer from them.

\subsubsection{In vitro release of CRV sponge:}

BLS sponge and CRV sponge equivalent to $6.25 \mathrm{mg}$ CRV was transferred to a dialysis bag (cutoff 12-14 KDa (and immersed into $250 \mathrm{~mL}$ PBS pH 6.8 containing $0.5 \%$ sodium lauryl sulfate and the cumulative \% of CRV released was conducted as previously discussed (section 2.4.3.) up to $24 \mathrm{~h}$.

\subsubsection{DSC of sponge}

DSC thermograms of CRV pure powder, CMC, CRV- CMC physical mixture, HPC, CRV- HPC physical mixture, and the prepared sponge were identified using Shimadzu differential scanning calorimeter (DSC-50, Kyoto, Japan). About $2 \mathrm{mg}$ of each sample was subjected to 
heat in a range of 10 to $300^{\circ} \mathrm{C}$ at a constant heating rate of $10^{\circ} \mathrm{C} / \mathrm{min}$ in a standard aluminum pot under an inert nitrogen flow of $25 \mathrm{ml} / \mathrm{min}$.

\subsubsection{Sponge morphology}

The morphology of the CMC-HPC /CRV- optimum BLS sponge was observed by scanning electron microscopy (Quanta $250 \mathrm{FEG}$, FEI Co) under a low vacuum at 200x magnification [10].

\subsection{In vivo studies}

\subsubsection{Experimental animals}

Male rats (180-200 g) were used. The study protocol was agreed upon by the research ethics committee, Suez Canal University, Egypt (201804RA2). Twenty-four rats were categorized into four groups, housed in different cages. Rats were freely allowed to food and water at a $12 \mathrm{~h}$ light/12 $\mathrm{h}$ dark cycle at room temperature $\left(25 \pm 1^{\circ} \mathrm{C}\right)$. They were supplied with a nutritionally appropriate standard laboratory diet.

\subsubsection{Experimental protocol}

The first group of rats was receiving $0.5 \% \mathrm{CMC}$ orally (control group). The second group was subjected to intraperitoneal injection with cadmium chloride ( $1 \mathrm{mg} / \mathrm{kg}$ b.wt./day) for 14 days followed by administering $0.5 \% \mathrm{CMC}$ as a vehicle orally for another 14 days [19] [20]. The third group was injected intraperitoneally with cadmium chloride for 14 days followed by buccal administration of BL-SP equivalent to $6.25 \mathrm{mg} / \mathrm{kg}$ CRV for another consecutive 14 days. The fourth group was injected intraperitoneally with cadmium chloride for 14 days followed by oral administration with Carvid $^{\circledR}(6.25 \mathrm{mg} / \mathrm{kg}$ in $0.5 \% \mathrm{CMC})$ daily for another 14 days.

At the end of the experiment, rats were killed, and blood samples were collected in absence of an anticoagulant. The separated serum was used for the assessment of lactate dehydrogenase [21] and creatine phosphokinase [22] activities using commercial enzymatic kits (Reactivos GPL, Barcelona, Spain). Cholesterol, LDL, HDL, and TG were assessed too. Also, total antioxidant capacity (TAC) was assessed using a commercial kit (Biodiagnostic, Egypt). All measurements were performed according to the catalog-instruction guidelines.

\subsubsection{Heart homogenate isolation}

The heart of each animal was excised instantly, washed with saline, and stored at $-80 \stackrel{\circ}{ } \mathrm{C}$. A piece of the heart was weighed and homogenized (10\%) in chilled $50 \mathrm{mmol}$ phosphate- 
buffered saline ( $\mathrm{pH} 7.4$ ), centrifuged for $15 \mathrm{~min}$ at 1200 and $4{ }^{\circ} \mathrm{C}$ using a cooling centrifuge (Sigma 30K, Germany), then the supernatants were used for the detection of the oxidative stress parameters.

\subsubsection{Lipid peroxidation determination (LPO)}

Lipid peroxidation (LPO) measurement of the heart was done by a colorimetric reaction with thiobarbituric acid as described by [23].

\subsubsection{Determination of Nitric oxide (NO)}

Nitric oxide was estimated as nitrite concentration. The technique used depends on the Griess reaction, which converts nitrite to a deep purple azo-compound, that measured photometrically at $540 \mathrm{~nm}$ according to [24].

\subsubsection{Reactive oxygen species determination (ROS)}

This test measures the intracellular conversion of nitro blue tetrazolium (NBT) to formazan by superoxide anion, which was used to measure the production of reactive oxygen species (ROS) as described by [25].

\subsection{Histopathological examination}

In different groups, autopsy samples were taken from the heart of rats and fixed for 24 hours in 10 percent formal saline. Wash was performed in tap water supplemented by serial alcohol dilutions (methyl, ethyl, and absolute ethyl) used for dehydration. Specimens were cleared in xylene and submerged for $24 \mathrm{~h}$ in hot air ovens at $56^{\circ} \mathrm{C}$. The tissues were examined by the light electric microscope [26].

\subsection{Statistical analysis}

In vivo results are presented as the mean of six replicates \pm standard error (SE) and statistically presented using GraphPad Prism 8 (GraphPad Software, CA). Values were compared by oneway analysis of variance (ANOVA). Post hoc testing was done for inter-group comparisons using Tukey's multiple comparisons test. Differences were considered statistically significant at $p \leq 0.05$.

\section{Results and discussion}

\subsection{Preparation and characterization of the BLS}


Bilosomes were successfully prepared by thin-film hydration-sonication technique producing homogenous dispersion. No precipitation or coagulation was observed.

\subsubsection{Physical characterization of bilosomes}

The mean size, PDI, and ZP of the prepared bilosomes are shown in Table 3. Fig. 1a shows the effect of the two independent variables on the PS. High lipid concentration(3\%) produced significantly $(P<0.0001)$ smaller bilosomes as it has a great surface area that accommodates CRV into the vesicle bilayer showing enhanced packing of vesicles and consequently particle size decrease [27]. The same findings were obtained by El Menshawe et al. upon preparing terbutaline bilosome; using high lipid level result in size reduction of the prepared bilosome [28].

High cholesterol concentration also had a significant effect $(P=0.002)$ on the PS of bilosomes. As the cholesterol concentration increased, the particle size decreased. This might be attributed to that cholesterol making the bilayer to be more compact [28]. This is in agreement with the results stated by [29] who found that cholesterol concentration had a significant impact in reducing the PS of lycopene-in- $\beta-C D$ - phospholipid vesicles.

The data of polydispersity index (PDI) showed a homogenous distribution of the studied vesicular systems as all values are less than 0.7 which designates the narrow size distribution of particles [30].

It was also observed that the prepared bilosomes confirmed satisfactory ZP values around \pm 30 $\mathrm{mV}$ that confirm their stability due to electrical repulsion between particles [31] [6] [30].

\subsubsection{Entrapment efficiency (EE\%) and drug loading (DL):}

The EE\% and DL of all bilosomes is shown in Table 3. It was observed that there was a direct correlation between $\mathrm{DL}$ and $\mathrm{EE} \%$ at the same lipid concentration. The ANOVA results illustrated in Fig. 1b shows that increasing lipid concentration significantly $(p<0.0001)$ increased EE\% due to high surface area obtained from a high concentration of lipid bilayer vesicles of CRV- BLS incorporated into the bio-membrane of phospholipid [32]. Furthermore, higher lipid concentration may provide more lipophilic area that accommodates lipophilic CRV which consequently leads to an increase in EE\% [33].

Furthermore, it was observed that the higher cholesterol concentration gave significantly $(p<0.0001)$ higher EE\% than the lower concentration. This is in agreement with the findings reported by [34]. who stated that the addition of cholesterol boosted the encapsulation 
efficiency of nevirapine when compared to formulae without cholesterol. Besides, the cementing outcome of cholesterol on the membrane packing prevented the drug efflux from the vesicles [28].

\subsubsection{In vitro drug release study}

Figure 2a showed that the prepared bilosomes generally sustained the release of CRV when compared to a drug suspension. Additionally, all the formulated bilosomes had biphasic release profiles with quick release in the initial 3 hours (ranged from 20.03 to 44.67\%) followed by a sustained release profile till $24 \mathrm{~h}$. The initial fast release may probably be due to the presence of the drug in the outer shell of the bilosome vesicles [35].

Moreover, the ANOVA results (figure (2b)) revealed that the lipid concentration (X1) showed a significant impact $(p<0.05)$ on the Q24 $h$ of the prepared bilosomes formulae, which could be due to the amphiphilic properties of soya bean phosphatidylcholine (SPC). Also, as previously stated in the PS evaluation, the high lipid concentration gave small PS; therefore, the boom in the percentage of CRV release is predictable [27]. In contrast, cholesterol concentration (X2) does not show any significant effect on Q24 $\mathrm{h}$ of the prepared BLS formulae. Mathematical analysis of CRV release data showed that the drug diffusion from the majority of the formulated bilosomes dispersions obeyed the Higuchi kinetics release model, illustrating a diffusion-controlled mechanism [15], while CRV suspension showed first-order kinetics.

\subsubsection{Ex-vivo permeation studies}

Table 4 and figure $2 c$ illustrate the results of CRV permeation obtained from different bilosomes formulae (BL1-BL9) in comparison with CRV suspension. The flux of CRV via the buccal membrane from CRV suspension was lower than all nine bilosomes formulae. Based on the permeation profiles, the total drug concentration permeated and Jmax, it can be concluded that the encapsulation of CRV in bilosome vesicles leads to a significant permeation improvement $(p<0.05)$ across the mucosal membrane relative to the control CRV suspension with a 2.9-fold increase. This may be attributed to the small vesicle size of CRV BLS thus increased their permeability [27].

Also, formula BL9 possessed higher permeability parameters relative to the other bilosomes formulae and CRV control suspension. This may be ascribed to the small PS and high concentration of phospholipids which increase the formula affinity to the biological membranes thus increasing its permeation [36]. 


\subsubsection{Selection of the optimum CRV loaded bilosome formula.}

The optimum formula was selected to have the least PS with maximum entrapment efficiency and maximum cumulative percent of CRV released after $24 \mathrm{~h}$ (Q24). Numerical analysis for results using the Design Expert $^{\circledR}$ software showed that the formula BL9, containing lipid concentration (3\%) and cholesterol (30\% w/w for total lipid), had the highest desirability value (0.861). Accordingly, it was chosen as the optimum formula among all other formulations for further investigations.

\subsection{Confocal laser scanning microscopy (CLSM) study}

Confocal laser scanning microscopy (CLSM) is a useful image tool to study the fate of bilosomes into the mucosal membrane. The optimum bilosomes formula (BL9) was selected for this study. As illustrated in Figure 3, CLSM study results showed that bilosomal formula BL9 was severely penetrated across the mucosal membrane with great fluorescence intensity and homogeneous distribution compared to rhodamine B solution. This deep penetration is evident for the potential of buccal bilosome as a penetration enhancer. These results settle well with the ex-vivo permeation study. The same results were achieved by Aboud et al. [15] who found that there is a deep penetration of CRV vesicles to nasal mucosa compared to rhodamine B solution.

\subsection{Differential scanning calorimetry (DSC)}

As shown in figure 6 , the DSC thermogram of pure CRV unveiled a melting endotherm at $116^{\circ} \mathrm{C}$, corresponding to its melting point. Consistently, soya bean phosphatidylcholine (SPC) exhibited three endothermic peaks at $134.69^{\circ} \mathrm{C}, 173.03^{\circ} \mathrm{C}$, and $274.93^{\circ} \mathrm{C}$, while sodium deoxycholate $(\mathrm{SDC})$ showed an endothermic peak at $77.3^{\circ} \mathrm{C}$ corresponding to its melting temperature. In the lyophilized optimized bilosome formulation thermogram, CRV endothermic peak disappeared, signifying that the drug is completely entrapped throughout the formulation [15].

\subsection{Transmission Electron Microscope (TEM)}

The TEM micrograph of the optimum bilosome formulation (BL9) is established in Figure 4a. It is clearly shown that it exists in well-identified small unilamellar vesicles with a spherical shape. No accumulation or drug crystals were detected.

\subsection{Stability study}


After three months of storage at $4-8^{\circ} \mathrm{C}$, there was no obvious alteration in the appearance of the bilosome dispersion (BL9) as shown in table 5. A non-significant difference was observed $(p>0.05)$ in the EE\% and PS of the stored bilosomes in comparison to the fresh ones. This indicates the physical stability of bilosomal dispersion under the storage condition.

\subsection{Preparation of CMC-HPC /CRV-BLS sponge}

BL9 bilosomes loaded sponge and non-vesicular CRV sponge were successfully prepared by the solvent casting method. The lyophilized sponge had a smooth surface texture with a porous structure. The porous structure of the sponge is created after water removal during lyophilization.

\subsection{Characterization of CMC-HPC /CRV-BLS sponge}

Data of sponge characterization is shown in table 6. The sponge $\mathrm{pH}$ was found to be around neutral, thus does not irritate the buccal mucosa [37]. The swelling was adequate (figure 7) to be an adhesive buccal system and confirming controlled CRV release. The sponge residence time was suitable for making a connection with buccal mucosa helping to wet the dosage form with the mucosal substrate, thus allowing the interpenetration of polymeric chains into the mucus film [10]. BL9 sponge showed improved porosity concerning CRV sponge (Figure 8) due to the incorporation of bilosome vesicles (nanoparticles) in the suspension form, consequently, lyophilization would produce a highly porous structure [18].

Figure $2 \mathrm{~d}$ shows that the percent CRV release from BL9 sponge after $12 \mathrm{~h}$ was much slower than sponge containing CRV, $64.77 \% \pm 0.87$ and $84.83 \% \pm 1.04$, respectively. This may be due to that upon sponge hydration, the polymer regains its gel structure leading to an increase in diffusional path length of the drug which may delay the release [18].

The thick gel layer of the swollen surface of the sponge can prevent the disintegration of the matrix and thus regulate further water penetration to slow down the release of the drug. In the case of the CRV sponge, the gel matrix effect on the drug release was minimal due to the presence of the drug dispersed into the sponge. Whereas BL9 sponge contains CRV encapsulated into bilosomes which may greatly delay the drug release [10].

DSC thermograms of sponge polymers showed that pure CRV displayed an endotherm peak at $116^{\circ} \mathrm{C}$, equivalent to its melting point. Likewise, $\mathrm{CMC}$ displayed an endotherm peak at $89^{\circ} \mathrm{C}$ matching its thermal melting point. HPC showed an endothermic peak at $45^{\circ} \mathrm{C}$ corresponding to its melting point. The melting peak of CRV in the CRV-CMC-HPC physical mixture has not 
changed indicating no interaction between them. While the melting peak of CRV vanished in the sponge as shown in figure 9 due to encapsulation into bilosomes inside the sponge [38]. The SEM micrographs of BL9 loaded sponge illustrates a porous structure as shown in figure $4 \mathrm{~b}$. This porous structure has resulted from the lyophilization process. The removal of water from the BL9 dispersion incorporated into the sponge by lyophilization created the vacant spaces which contributed to the recognized large number of uniform pores [18].

\subsection{In-vivo studies}

\subsubsection{Effect on body weight (BW) and blood pressure (BP)}

It was observed that the Cadmium exposure leads to a decrease in BW and increase in BP compared to the control group (Figure 10).

BW was significantly increased, and BP was significantly decreased after treatment of BLSP and Carvid $^{\circledR}$ compared to the $\mathrm{CdCl}_{2}$ group.

The present study revealed that cadmium chloride $\left(\mathrm{CdCl}_{2} 1.0 \mathrm{mg} / \mathrm{kg}\right.$, i.p.) treatment in albino rats for 15 days resulted in the elevation of blood pressure figure 11 .

Our results illustrated that systolic and diastolic B.P. significantly decrease in BL-SP $(6.25$ $\mathrm{mg} / \mathrm{kg}$, buccally) and Carvid@ (6.25 mg/kg, orally) groups for 28 days.

In agreement with our findings, it has been shown that carvedilol is a multiple action antihypertensive drug currently marketed for the treatment of mild to moderate hypertension [39].

\subsubsection{Effect on the serum heart marker enzymes}

In the present study, there is a marked elevation in the serum lactate dehydrogenase (LDH) and creatine kinase ( $\mathrm{CK}$ ) activities for $\mathrm{CdCl}$-intoxicated rats as compared to the control animals (Figure 12). However, pre-treatment of BLSP and Carvid ${ }^{\circledR}$ resulted in a significant $(P<0.05)$ reduction in the activities of these enzymes as compared to the $\mathrm{CdCl}$-intoxicated rats. These enzymes are released to the bloodstream from the heart, which mirrors the alterations in myocardial membrane permeability [40]. The efficacy of BLSP and Carvid ${ }^{\circledR}$ on Cd-induced hypertensive rats might be due to the powerful antioxidant activity of BLSP or Carvid $^{\circledR}$ that reduces the LDH and CK enzyme activities, therefore limiting the seepage of CK and LDH enzymes from myocardium representing reduced myocardial impairment. The effect of the BL9 sponge was more significant in restoring cardiac enzymes to their normal values as 
in the negative control group that does not receive any treatment which was beneficial in maintaining the normal cardiac function.

\subsubsection{Effect serum lipid profile parameters}

Figure (13) showed the lipid profile determined in the serum of various experimental groups. Cholesterol, HDL, LDL, and TG levels in serum showed significant elevations $(P<0.05)$ in $\mathrm{CdCl}$ treated rats' group as compared to the normal ones. However, BLSP and Carvid ${ }^{\circledR}$ pretreatment significantly decreased the levels of Cholesterol, HDL, LDL, and TG as compared to the corresponding $\mathrm{CdCl} 2$ treated group with a higher effect of BLSP than $\mathrm{Carvid}^{\circledR}$ which was due to better penetration of BLSP to the buccal membrane as shown in confocal microscope study. The gathering of cholesterol on the blood vessels wall causes atherosclerosis, which rises with age [40].

Efficacy of BLS sponge and Carvid ${ }^{\circledR}$ in lessening the levels of cholesterol, LDL, and TG with increasing effect on HDL that may be linked to the blocking action of Carvedilol to the oxidation pathway of low-density lipoproteins (LDL). Therefore, it prevents the creation of oxidized-LDL which enhances the formation of atherosclerotic plaque. Thus, avoids endothelial destruction [39]. This effect was more observed in BLSP than Carvid ${ }^{\circledR}$ which may be due to better penetration of the vesicular system(bilosome) in the sponge to the buccal membrane rather than Carvid ${ }^{\circledR}$ tablet which was orally administered and destroyed by hepatic enzymes in the first-pass metabolism [30].

\subsubsection{Effect of sponge and Carvid $^{\circledR}$ on oxidative stress parameters}

The administration of $\mathrm{CdCl} 2$ significantly $(\mathrm{P}<0.05)$ elevated the oxidative stress parameters content in the heart as ROS, LPO, and decreased NO and TAC levels compared to the control group. This effect plays a major role in vascular dysfunction [41].

BLSP and Carvid ${ }^{\circledast}$ treatments significantly $(P<0.05)$ decreased the heart contents of ROS, lipid peroxide while increasing the content of NO, and TCA compared to the $\mathrm{CdCl} 2$-treated animals (Fig. 14).

Besides its action as a $\beta$-blocker, CRV presents an antioxidant capacity due to a carbazole moiety [42] [43]. It has been proposed that CRV has two antioxidant mechanisms: chelation of ferrous ions and/or hunting of free radicals [44].

Normally, electron-donor atoms on the chelating molecule include sulfur, nitrogen, and/or oxygen [45]. The chelation of free iron inhibits the Fenton reaction and consequently the 
formation of hydroxyl radicals, a highly reactive oxygen species that cannot be detoxified by enzymatic reactions [46]. Therefore, this mechanism supports the effectiveness of CRV against the cardiotoxicity induced by cadmium. These findings are in line with our results which revealed that CRV and BLSP reduce lipid peroxidation and ROS levels and increase total antioxidant capacity (TAC) in heart rats treated with cadmium [47].

$\mathrm{Cd}$ induces endothelial dysfunction resulting from a reduction in $\mathrm{NO} \bullet$ bioavailability through oxidative stress which causes altering $\mathrm{NO} \bullet$ metabolism [48]. revealed that Cd exposure causes an increase in $\mathrm{O} 2 \bullet-$ production in the thoracic aorta, and this could effectively scavenge NO to form strong oxidant peroxynitrite (ONOO-). In agreement with our findings, It has been reported a reduction in serum NO levels in cadmium-treated rats may play a role in the observed reduction in endothelium-dependent relaxation responses in cadmiumhypertensive rats [49]. Treatment with Carvid or BLSP markedly increased NO level. It might result in reduced formation of peroxynitrite in the endothelial cells and increase the bioavailability of NO through scavenging superoxide ions and inhibiting the production of superoxide radicals [50].

\subsection{Histopathological examination}

The purpose of this examination is to explore the cardio protection effect of different formulae on the tissue's organization. Photographs of stained histological samples of normal, $\mathrm{CdCl}_{2}$ treated, Carvid $^{\circledR}$ and BLSP rats' hearts are established in Figure 5.

Normal rats' heart section Figure 5(a) discovered no histological change in the structure of the myocardial cells. Untreated $\mathrm{CdCl} 2$ poisoned rat heart section (Figure $5 \mathrm{~b} \& \mathrm{c}$ ) showed a focal fatty change in some myocardial cells allied with blood vascular spaces lined by injured endothelium in the myocardium. Also, there was edema with inflammatory cells in the pericardium. Post-treatment with $\mathrm{Carvid}^{\circledR}$ after $\mathrm{CdCl} 2$ induction Figure 5 (d) showed mild dilatation in the myocardial blood capillaries. Finally, Post-treatment with BLSP after $\mathrm{CdCl} 2$ initiation Figure 5(e) showed Focal few inflammatory cells in the myocardium linked with mild dilatation in the myocardial blood vessels. This indicates potential BLSP as an inventive cardioprotective treatment.

\section{Conclusion}

The optimized bilosomes formula BL9 was constructed with a focus on surface response analysis. The use of high lipid concentration has a significant effect in reducing particle size, optimizing entrapment, and great enhancement in the buccal permeability. These findings 
were like CLSM images which show deeper penetration of bilosomes through sheep buccal mucosa relative to rhodamine B solution. Also, a bilosomes loaded sponge was successfully prepared using a $2 \% \mathrm{~W} / \mathrm{V} \mathrm{CMC/HPC}$ polymer blend with satisfactory characteristics and respectable residence time that allow enough contact time for penetration. In vivo study revealed significant enhancement in SBP, DBP, oxidative stress biomarkers, cardiac markers, and lipid profile. Histopathological studies showed the superiority of BL9 sponge in the protection of heart tissues over Carvid ${ }^{\circledR}$. Accordingly, the data collected recommended that bilosomes based sponge give a talented improvement in the buccal delivery of CRV with better efficacy in the protection of heart tissue over the current product (Carvid $\left.{ }^{\circledR}\right)$.

\section{Author's Contributions}

All six authors contributed to the manuscript. All were involved in the design of the study. NS is responsible for material preparation, data collection and analysis. RS was a major contributor in interpreting the data and writing the manuscript. MA performed the vivo analysis on rats. EK and MG commented on previous versions of the manuscript. The study was under supervision of SG. All authors read and approved the final manuscript.

\section{Data Availability}

Availability of data and material has been described in the manuscript. They are freely available to any scientist who wishes to use them without breaching participant confidentiality.

\section{Compliance with Ethical Standards}

Conflicts of Interest: The authors declare that they have no competing interests.

Statement of Ethics Committee Approval: The in-vivo study protocol on rats was agreed upon by the research ethics committee, Suez Canal University, Egypt (201804RA2).

\section{References}

[1] S. Halder, F. Ahmed, M. L. Shuma, M. A. K. Azad, and E. R. Kabir, "Impact of drying on dissolution behavior of carvedilol-loaded sustained-release solid dispersion: development and characterization," Heliyon, vol. 6, no. 9, p. e05026, 2020, doi: 10.1016/j.heliyon.2020.e05026. 
[2] G. Neugebauer, W. Akpan, B. Kaufmann, and K. Reiff, "Stereoselective disposition of carvedilol in man after intravenous and oral administration of the racemic compound," Eur. J. Clin. Pharmacol., vol. 38, no. 2 Supplement, pp. 108-111, 1990, doi: 10.1007/BF01409476.

[3] M. N. Pham, T. Van Vo, V. Tran, P. H. Tran, and T. T. Tran, "Microemulsion-Based Mucoadhesive Buccal Wafers : Wafer Formation, In Vitro Release, and Ex Vivo Evaluation," vol. 18, no. 7, 2017, doi: 10.1208/s12249-017-0754-9.

[4] H. Abd El Azim, N. Nafee, A. Ramadan, and N. Khalafallah, "Liposomal buccal mucoadhesive film for improved delivery and permeation of water-soluble vitamins," Int. J. Pharm., vol. 488, no. 1-2, pp. 78-85, 2015, doi: 10.1016/j.ijpharm.2015.04.052.

[5] M. Cui, W. Wu, L. Hovgaard, Y. Lu, D. Chen, and J. Qi, "Liposomes containing cholesterol analogues of botanical origin as drug delivery systems to enhance the oral absorption of insulin," Int. J. Pharm., vol. 489, no. 1-2, pp. 277-284, 2015, doi: 10.1016/j.ijpharm.2015.05.006.

[6] A. Abd-Elbary, A. M. A. Makky, M. I. Tadros, and A. A. Alaa-Eldin, "Laminated sponges as challenging solid hydrophilic matrices for the buccal delivery of carvedilol microemulsion systems: Development and proof of concept via mucoadhesion and pharmacokinetic assessments in healthy human volunteers," Eur. J. Pharm. Sci., vol. 82, pp. 31-44, 2016, doi: 10.1016/j.ejps.2015.11.006.

[7] M. S. El-Samaligy, N. N. Afifi, and E. A. Mahmoud, "Increasing bioavailability of silymarin using a buccal liposomal delivery system: Preparation and experimental design investigation," Int. J. Pharm., vol. 308, no. 1-2, pp. 140-148, 2006, doi: 10.1016/j.ijpharm.2005.11.006.

[8] T. Z. Yang, X. T. Wang, X. Y. Yan, and Q. Zhang, "Phospholipid deformable vesicles for buccal delivery of insulin," Chem. Pharm. Bull., vol. 50, no. 6, pp. 749-753, 2002, doi: 10.1248/cpb.50.749.

[9] M. L. C. Portero, A Osorio DT Alonso, "Development of chitosan sponges for buccal administration of insulin," vol. 68, pp. 617-625, 2007, doi: 10.1016/j.carbpol.2006.07.028.

[10] H. A. Hazzah, R. M. Farid, M. M. A. Nasra, M. A. El-Massik, and O. Y. Abdallah, "Lyophilized sponges loaded with curcumin solid lipid nanoparticles for buccal 
delivery: Development and characterization," Int. J. Pharm., vol. 492, no. 1-2, pp. 248-257, 2015, doi: 10.1016/j.ijpharm.2015.06.022.

[11] T. Heinze and A. Koschella, "Carboxymethyl ethers of cellulose and starch - A review," Macromol. Symp., vol. 223, no. March 2005, pp. 13-39, 2005, doi: 10.1002/masy.200550502.

[12] S. P. Hoo, L. Loh, Z. Yue, J. Fu, T. T. Y. Tan, and P. P. Y. Chan, "Preparation of a soft and interconnected macroporous hydroxypropyl cellulose methacrylate sca ff old for adipose tissue engineering," pp. 3107-3117, 2013, doi: 10.1039/c3tb00446e.

[13] S. A. Rahman, N. S. Abdelmalak, A. Badawi, T. Elbayoumy, N. Sabry, and A. El Ramly, "Tretinoin-loaded liposomal formulations: from lab to comparative clinical study in acne patients," Drug Deliv., vol. 23, no. 4, pp. 1184-1193, 2016, doi: 10.3109/10717544.2015.1041578.

[14] E. Moghimipour, M. Tafaghodi, A. Balouchi, and S. Handali, "Formulation and in vitro evaluation of topical liposomal gel of Triamcinolone acetonide," Res. J. Pharm. Biol. Chem. Sci., vol. 4, no. 1, pp. 101-107, 2013.

[15] H. M. Aboud, A. A. Ali, S. F. El-Menshawe, and A. A. Elbary, "Nanotransfersomes of carvedilol for intranasal delivery: formulation, characterization and in vivo evaluation," Drug Deliv., vol. 23, no. 7, pp. 2471-2481, 2016, doi: 10.3109/10717544.2015.1013587.

[16] M. A. El-Nabarawi, R. N. Shamma, F. Farouk, and S. M. Nasralla, "Bilosomes as a novel carrier for the cutaneous delivery for dapsone as a potential treatment of acne: preparation, characterization and in vivo skin deposition assay," J. Liposome Res., vol. 30, no. 1, pp. 1-11, 2019, doi: 10.1080/08982104.2019.1577256.

[17] M. A. A. Kassem, A. N. ElMeshad, and A. R. Fares, "Lyophilized Sustained Release Mucoadhesive Chitosan Sponges for Buccal Buspirone Hydrochloride Delivery: Formulation and In Vitro Evaluation," AAPS PharmSciTech, vol. 16, no. 3, pp. 537547, 2015, doi: 10.1208/s12249-014-0243-3.

[18] R. A. B. Sanad and H. M. Abdel-Bar, Chitosan-hyaluronic acid composite sponge scaffold enriched with Andrographolide-loaded lipid nanoparticles for enhanced wound healing, vol. 173. Elsevier Ltd., 2017.

[19] Alamgeer et al., "Evaluation of antihypertensive effect of aqueous methanol extract 
of caralluma tuberculata N.E.Br in sprauge dawley rats," Trop. J. Pharm. Res., vol. 14, no. 3, pp. 455-462, 2015, doi: 10.4314/tjpr.v14i3.14.

[20] C. O. Olaiya, T. O. Omolekan, A. M. Esan, and B. J. Adediran, "Renal, cardiac and osteo - protective effects of beta - sitosterol glycoside in hypertensive rats," Adv. Life Sci. Technol., vol. 39, pp. 13-18, 2015, [Online]. Available:

http://citeseerx.ist.psu.edu/viewdoc/download?doi=10.1.1.735.1482\&rep=rep1\&typ $\mathrm{e}=\mathrm{pdf}$.

[21] S. N. Buhl and K. Y. Jackson, "Optimal conditions and comparison of lactate dehydrogenase catalysis of the lactate to pyruvate and pyruvate to lactate reactions in human serum at 25, 30, and 37??C.," Clin. Chem., vol. 24, no. 5, pp. 828-831, 1978.

[22] G. Szasz, W. Gruber, and E. Bernt, "Creatine kinase in serum: I. Determination of optimum reaction conditions," Clin. Chem., vol. 22, no. 5, pp. 650-656, 1976.

[23] M. Uchiyama and M. Mihara, "Determination of malonaldehyde precursor in tissues by thiobarbituric acid test," Anal. Biochem., vol. 86, no. 1, pp. 271-278, 1978, doi: 10.1016/0003-2697(78)90342-1.

[24] C. C. Wang, Y. J. Huang, L. G. Chen, L. T. Lee, and L. L. Yang, "Inducible nitric oxide synthase inhibitors of Chinese herbs III. Rheum palmatum," Planta Med., vol. 68, no. 10, pp. 869-874, 2002, doi: 10.1055/s-2002-34918.

[25] A. S. Vrablic, C. D. Albright, C. N. Craciunescu, R. I. Salganik, and S. H. Zeisel, "Altered mitochondrial function and overgeneration of reactive oxygen species precede the induction of apoptosis by 1-0-octadecyl-2-methyl-rac-glycero-3-phosphocholine in p53-defective hepatocytes," FASEB J., vol. 15, no. 10, pp. 1739-1744, 2001, doi: 10.1096/fj.00-0300com.

[26] Banchroft, J.D.; Stevens, A. And Turner , D.R. (1996).

[27] K. S. Avadhani et al., "Skin delivery of epigallocatechin-3-gallate (EGCG) and hyaluronic acid loaded nano-transfersomes for antioxidant and anti-aging effects in UV radiation induced skin damage," Drug Deliv., vol. 24, no. 1, pp. 61-74, 2017, doi: 10.1080/10717544.2016.1228718.

[28] S. F. El Menshawe, M. M. Nafady, H. M. Aboud, R. M. Kharshoum, A. M. M. H. Elkelawy, and D. S. Hamad, "Transdermal delivery of fluvastatin sodium via tailored spanlastic nanovesicles: mitigated Freund's adjuvant-induced rheumatoid arthritis in 
rats through suppressing p38 MAPK signaling pathway," Drug Deliv., vol. 26, no. 1, pp. $1140-1154,2019$, doi: 10.1080/10717544.2019.1686087.

[29] S. A. Rahman, N. S. Abdelmalak, A. Badawi, T. Elbayoumy, N. Sabry, and A. El Ramly, "Tretinoin-loaded liposomal formulations: from lab to comparative clinical study in acne patients," Drug Deliv., vol. 23, no. 4, pp. 1184-1193, 2016, doi: 10.3109/10717544.2015.1041578.

[30] A. A. H. Abdellatif, D. F. A. El-Telbany, G. Zayed, and M. M. Al-Sawahli, "Hydrogel Containing PEG-Coated Fluconazole Nanoparticles with Enhanced Solubility and Antifungal Activity," J. Pharm. Innov., vol. 14, no. 2, pp. 112-122, 2019, doi: 10.1007/s12247-018-9335-z.

[31] N. M. Sallam, R. A. B. Sanad, M. M. Ahmed, E. S. Khafagy, M. Ghorab, and S. Gad, "Impact of the mucoadhesive lyophilized wafer loaded with novel carvedilol nanospanlastics on biochemical markers in the heart of spontaneously hypertensive rat models," Drug Deliv. Transl. Res., 2020, doi: 10.1007/s13346-020-00814-4.

[32] K. Zhang, Y. Zhang, Z. Li, N. Li, and N. Feng, "Essential oil-mediated glycerosomes increase transdermal paeoniflorin delivery: Optimization, characterization, and evaluation in vitro and in vivo," Int. J. Nanomedicine, vol. 12, pp. 3521-3532, 2017, doi: 10.2147/IJN.S135749.

[33] S. F. El Menshawe, H. M. Aboud, M. H. Elkomy, R. M. Kharshoum, and A. M. Abdeltwab, "A novel nanogel loaded with chitosan decorated bilosomes for transdermal delivery of terbutaline sulfate: artificial neural network optimization, in vitro characterization and in vivo evaluation," Drug Deliv. Transl. Res., 2019, doi: 10.1007/s13346-019-00688-1.

[34] N. Karami, E. Moghimipour, and A. Salimi, "Liposomes as a novel drug delivery system: Fundamental and pharmaceutical application," Asian J. Pharm., vol. 12, no. 1, pp. S31-S41, 2018, doi: 10.22377/ajp.v12i01.2037.

[35] G. Natesan, B. Dhandayuthapani, P. Perumal, J. Balasundaram, and S. Natesan, "Design and characterization of ofloxacin niosomes," Pak. J. Pharm. Sci., vol. 26, no. 6, pp. 1089-1096, 2013.

[36] S. A. Tayel, M. A. El-Nabarawi, M. I. Tadros, and W. H. Abd-Elsalam, "Duodenumtriggered delivery of pravastatin sodium via enteric surface-coated nanovesicular 
spanlastic dispersions: Development, characterization and pharmacokinetic assessments," Int. J. Pharm., vol. 483, no. 1-2, pp. 77-88, 2015, doi: 10.1016/j.ijpharm.2015.02.012.

[37] M. L. González-Rodríguez et al., "Deformability properties of timolol-loaded transfersomes based on the extrusion mechanism. Statistical optimization of the process," Drug Dev. Ind. Pharm., vol. 42, no. 10, pp. 1683-1694, 2016, doi: 10.3109/03639045.2016.1165691.

[38] B. S. Anisha, D. Sankar, A. Mohandas, K. P. Chennazhi, S. V. Nair, and R. Jayakumar, "Chitosan-hyaluronan/nano chondroitin sulfate ternary composite sponges for medical use," Carbohydr. Polym., vol. 92, no. 2, pp. 1470-1476, 2013, doi: 10.1016/j.carbpol.2012.10.058.

[39] R. N. Shamma, S. Sayed, N. A. Sabry, and S. I. El-Samanoudy, "Enhanced skin targeting of retinoic acid spanlastics: in vitro characterization and clinical evaluation in acne patients," J. Liposome Res., vol. 2104, 2019, doi: 10.1080/08982104.2018.1552706.

[40] K. Watanabe et al., "Low dose carvedilol inhibits progression of heart failure in rats with dilated cardiomyopathy," Br. J. Pharmacol., vol. 130, no. 7, pp. 1489-1495, 2000, doi: 10.1038/sj.bjp.0703450.

[41] K. H. Sabeena Farvin, R. Anandan, S. H. S. Kumar, K. S. Shiny, T. V. Sankar, and T. K. Thankappan, "Effect of squalene on tissue defense system in isoproterenol-induced myocardial infarction in rats," Pharmacol. Res., vol. 50, no. 3, pp. 231-236, 2004, doi: 10.1016/j.phrs.2004.03.004.

[42] S. Amara et al., "Preventive effect of zinc against cadmium-induced oxidative stress in the rat testis," J. Reprod. Dev., vol. 54, no. 2, pp. 129-134, 2008, doi: 10.1262/jrd.18110.

[43] M. Pauschinger et al., "Carvedilol improves left ventricular function in murine coxsackievirus-induced acute myocarditis: Association with reduced myocardial interleukin-1 $\beta$ and MMP-8 expression and a modulated immune response," Eur. J. Heart Fail., vol. 7, no. 4, pp. 444-452, 2005, doi: 10.1016/j.ejheart.2004.07.002.

[44] P. C. Stafylas and P. A. Sarafidis, "Carvedilol in hypertension treatment," Vascular Health and Risk Management, vol. 4, no. 1. pp. 23-30, 2008, doi:

10.2147/vhrm.2008.04.01.23. 
[45] P. Dandona, H. Ghanim, and D. P. Brooks, "Antioxidant activity of carvedilol in cardiovascular disease," J. Hypertens., vol. 25, no. 4, pp. 731-741, 2007, doi: 10.1097/HJH.0b013e3280127948.

[46] M. E. Sears, "Chelation: Harnessing and enhancing heavy metal detoxification - A review," Sci. World J., vol. 2013, 2013, doi: 10.1155/2013/219840.

[47] T. Šimůnek, M. Štěrba, O. Popelová, M. Adamcová, R. Hrdina, and V. Gerši, "Anthracycline-induced cardiotoxicity: Overview of studies examining the roles of oxidative stress and free cellular iron," Pharmacol. Reports, vol. 61, no. 1, pp. 154171, 2009, doi: 10.1016/S1734-1140(09)70018-0.

[48] U. Kukongviriyapan, P. Pannangpetch, V. Kukongviriyapan, W. Donpunha, K. Sompamit, and P. Surawattanawan, "Curcumin protects against cadmium-induced vascular dysfunction, hypertension and tissue cadmium accumulation in mice," Nutrients, vol. 6, no. 3, pp. 1194-1208, 2014, doi: 10.3390/nu6031194.

[49] W. Donpunha, U. Kukongviriyapan, K. Sompamit, P. Pakdeechote, V. Kukongviriyapan, and P. Pannangpetch, "Protective effect of ascorbic acid on cadmium-induced hypertension and vascular dysfunction in mice," BioMetals, vol. 24, no. 1, pp. 105-115, 2011, doi: 10.1007/s10534-010-9379-0.

[50] T. L. Yue, R. R. Ruffolo, and G. Feuerstein, "Antioxidant action of carvedilol: A potential role in treatment of heart failure," Heart Fail. Rev., vol. 4, no. 1, pp. 39-51, 1999, doi: 10.1023/A:1009803817707. 


\section{Tables}

Table (1): The composition of the prepared CRV bilosomes (BLs) formulae*

\begin{tabular}{|l|l|l|}
\hline $\begin{array}{l}\text { Formula } \\
\text { code }\end{array}$ & $\begin{array}{l}\text { Lipid conc. } \\
\mathbf{( \% )}\end{array}$ & $\begin{array}{l}\text { Soya bean } \\
\text { phosphatidylcholine } \\
\text { conc. } \\
\mathbf{( \% w} / \mathbf{w} \text { of lipid) }\end{array}$ \\
\hline L1 & $1 \%$ & $100 \%$ \\
\hline L2 & $1 \%$ & $100 \%$ \\
\hline L3 & $1 \%$ & $100 \%$ \\
\hline L4 & $2 \%$ & $90 \%$ \\
\hline L5 & $2 \%$ & $90 \%$ \\
\hline L6 & $2 \%$ & $90 \%$ \\
\hline L7 & $3 \%$ & $70 \%$ \\
\hline L8 & $3 \%$ & $70 \%$ \\
\hline L9 & $3 \%$ & $70 \%$ \\
\hline
\end{tabular}

*Each formula contains $62.5 \mathrm{mg}$ CRV, Diacetyl phosphate $5 \% \mathrm{w} / \mathrm{w}$ of total lipid, and $25 \mathrm{mg}$ Sodium deoxycholate. 
Table (2): Factorial design $3^{2}$ for CRV loaded bilosomes (BLs) with their measured responses and their required constraints.

\begin{tabular}{|l|l|l|l|}
\hline Independent variables & \multicolumn{2}{|l|}{ levels } \\
\hline X1: Lipid concentration (\%) & $1 \%$ & $2 \%$ & $3 \%$ \\
\hline $\begin{array}{l}\text { X2: Cholesterol concentration } \\
\text { (w/w of lipid) }\end{array}$ & $0 \%$ & $10 \%$ & $30 \%$ \\
\hline Dependent variables & Required constraints \\
\hline Y1:EE (\%) & Maximize \\
\hline Y2:PS (nm) & Minimize \\
\hline Y3:Q24h (\%) & Maximize \\
\hline
\end{tabular}


Table (3): entrapment efficiency (E.E) drug loading (DL), particle size (P.S.), polydispersity index (PDI), and zeta potential (Z.P.) of different CRV-loaded bilosomes (BLS)

\begin{tabular}{|l|l|l|l|l|l|}
\hline $\begin{array}{l}\text { Formula } \\
\text { code }\end{array}$ & $\begin{array}{l}\text { E.E* } \\
(\%)\end{array}$ & DL* & $\begin{array}{l}\text { P.S* } \\
(\mathrm{nm})\end{array}$ & PDI* & $\begin{array}{l}\text { Z.P* } \\
(\mathrm{mv})\end{array}$ \\
\hline BL1 & $51.03 \pm 0.48$ & $1.86 \pm 0.04$ & $271.2 \pm 5.80$ & $0.41 \pm 0.005$ & $-28.54 \pm 3$ \\
\hline BL2 & $59.81 \pm 1.43$ & $2.15 \pm 0.04$ & $311.5 \pm 4.3$ & $0.54 \pm 0.003$ & $-26.11 \pm 3.7$ \\
\hline BL3 & $77.05 \pm 0.9$ & $2.26 \pm 0.03$ & $252.8 \pm 5.09$ & $0.67 \pm 0.004$ & $-33.57 \pm 1$ \\
\hline BL4 & $78.81 \pm 1.53$ & $1.1 \pm 0.00$ & $241.3 \pm 5.80$ & $0.36 \pm 0.015$ & $-34.81 \pm 2.1$ \\
\hline BL5 & $82.8 \pm 2.75$ & $1.12 \pm 0.04$ & $251.4 \pm 3.40$ & $0.37 \pm 0.006$ & $-34.7 \pm 2.93$ \\
\hline BL6 & $85.72 \pm 1.35$ & $1.15 \pm 0.02$ & $235.1 \pm 5.10$ & $0.21 \pm 0.004$ & $-38.11 \pm 1.01$ \\
\hline BL7 & $79.57 \pm 1.29$ & $0.73 \pm 0.01$ & $229.5 \pm 6.00$ & $0.43 \pm 0.003$ & $-37.55 \pm 1.95$ \\
\hline BL8 & $82.4 \pm 1.76$ & $0.75 \pm 0.01$ & $211.3 \pm 7.1$ & $0.43 \pm 0.002$ & $-43.3 \pm 1.04$ \\
\hline BL9 & $87.13 \pm 0.5$ & $0.78 \pm 0.02$ & $217.2 \pm 2$ & $0.18 \pm 0.002$ & $-46.1 \pm 1.1$ \\
\hline
\end{tabular}

$*$ Data are expressed as the mean $\pm \mathrm{SD}, \mathrm{n}=3$. 
Table (4): Ex vivo permeation parameters of different carvedilol-loaded bilosomes (CRV/BLS) versus carvedilol suspension(control)

\begin{tabular}{|c|c|c|c|c|}
\hline Formula code & $\begin{array}{l}\text { The total amount } \\
\text { of drug } \\
\text { permeated* } \\
(\mu \mathrm{g} / \mathrm{cm} 2)\end{array}$ & $\begin{array}{l}\text { Flux at } 24 \mathrm{~h}^{*} \\
(\mathrm{~J} \max ) \\
(\mu \mathrm{g} / \mathrm{cm} 2 / \mathrm{h})\end{array}$ & $\begin{array}{l}\text { Enhancement } \\
\text { Ratio* } \\
\text { (ER) }\end{array}$ & $\begin{array}{l}\text { Permeability } \\
\text { Coefficient* } \\
\text { (Cp) }\end{array}$ \\
\hline BL1 & $297 \pm 5.5$ & $12.37 \pm 0.33$ & 1.58 & $0.0036 \pm 0.0001$ \\
\hline BL2 & $324.8 \pm 3.2$ & $13.53 \pm 0.18$ & 1.73 & $0.0043 \pm 0.0002$ \\
\hline BL3 & $375 \pm 2$ & $15.62 \pm 0.11$ & 1.99 & $0.0060 \pm 0.0003$ \\
\hline BL4 & $403.97 \pm 3.55$ & $16.83 \pm 0.21$ & 2.15 & $0.0046 \pm 0.0004$ \\
\hline BL5 & $412.3 \pm 3.20$ & $17.04 \pm 0.21$ & 2.18 & $0.0063 \pm 0.0004$ \\
\hline BL6 & $422.33 \pm 3.21$ & $19.67 \pm 3.10$ & 2.52 & $0.0069 \pm 0.0005$ \\
\hline BL7 & $455 \pm 3.5$ & $18.96 \pm 0.21$ & 2.42 & $0.0069 \pm 0.00006$ \\
\hline BL8 & $506.33 \pm 5.31$ & $21.11 \pm 0.31$ & 2.7 & $0.0070 \pm 0.0005$ \\
\hline BL9 & $548.43 \pm 6.98$ & $22.82 \pm 0.41$ & 2.91 & $0.0017 \pm 0.0003$ \\
\hline $\begin{array}{l}\text { Carvedilol } \\
\text { suspension }\end{array}$ & $188 \pm 1.9$ & $7.83 \pm 0.11$ & - & $0.0017 \pm 0.0000$ \\
\hline
\end{tabular}

$*$ Data presented are mean $\pm S D, n=3$. Statistically significant difference at $\mathrm{P}<0.05$ from control 
Table (5): Effect of storage on the physical properties of the optimized CRV bilosomal formulation (BL9).

\begin{tabular}{|l|l|l|}
\hline Parameter & $\begin{array}{l}\text { Freshly prepared bilosomal } \\
\text { formulation }\end{array}$ & $\begin{array}{l}\text { After 3 months of storage at } \\
\text { refrigerator }\end{array}$ \\
\hline EE (\%) & $87.13 \pm 0.5$ & $84.5 \pm 1.25$ \\
\hline PS (nm) & $217.2 \pm 2$ & $229.4 \pm 2.65$ \\
\hline
\end{tabular}


Table (6): In vitro characterization of BL9 loaded sponge:

\begin{tabular}{|l|l|}
\hline Parameter* & BL9 loaded sponge \\
\hline $\begin{array}{l}\text { Drug content } \\
(\%)\end{array}$ & $97.75 \pm 0.92$ \\
\hline $\mathrm{pH}$ & $6.5 \pm 0.22$ \\
\hline $\begin{array}{l}\text { Disintegration } \\
(\mathrm{min})\end{array}$ & $232.5 \pm 3.54$ \\
\hline Residence time(min) & $170 \pm 2.83$ \\
\hline
\end{tabular}

*Data presented are mean $\pm \mathrm{SD}, \mathrm{n}=3$ 
Figures

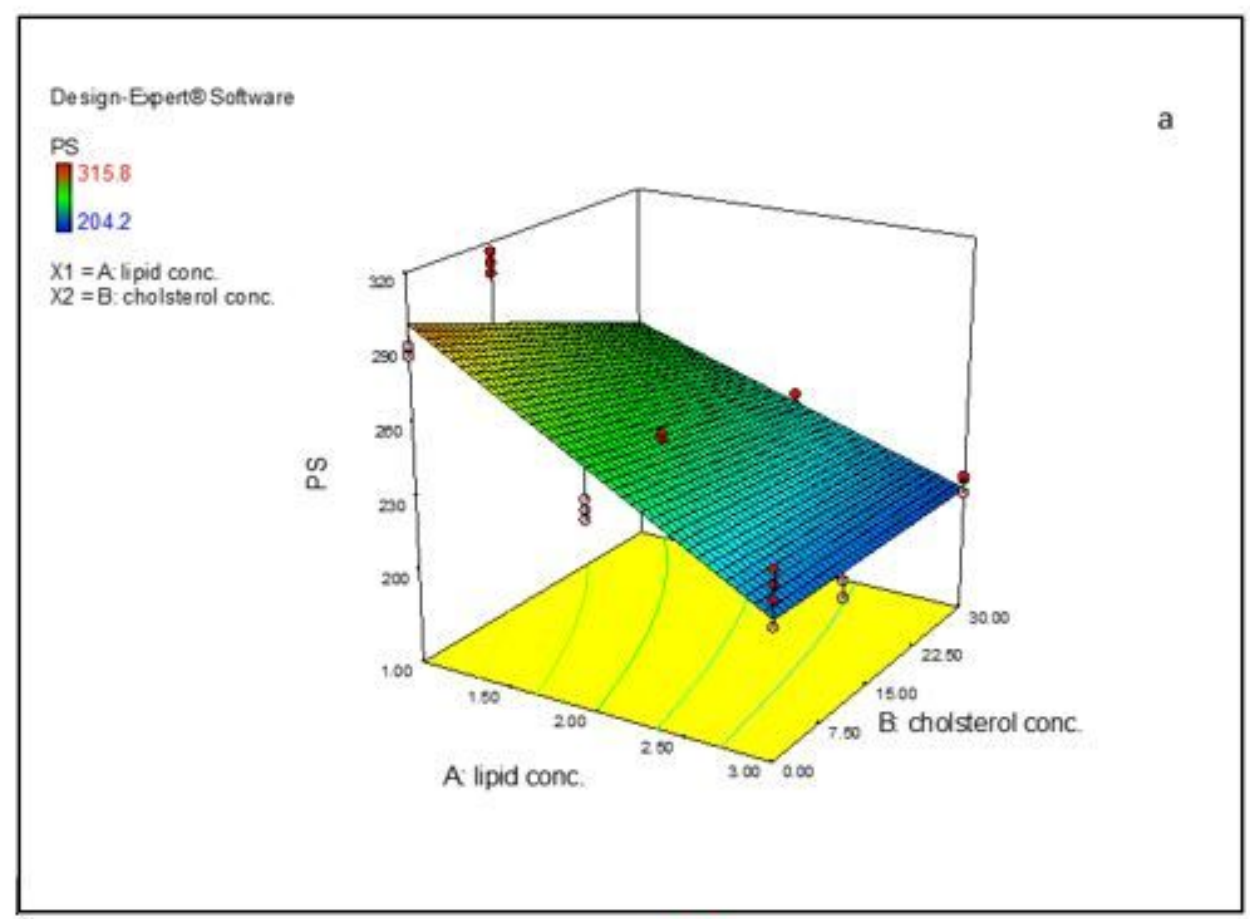

(a)

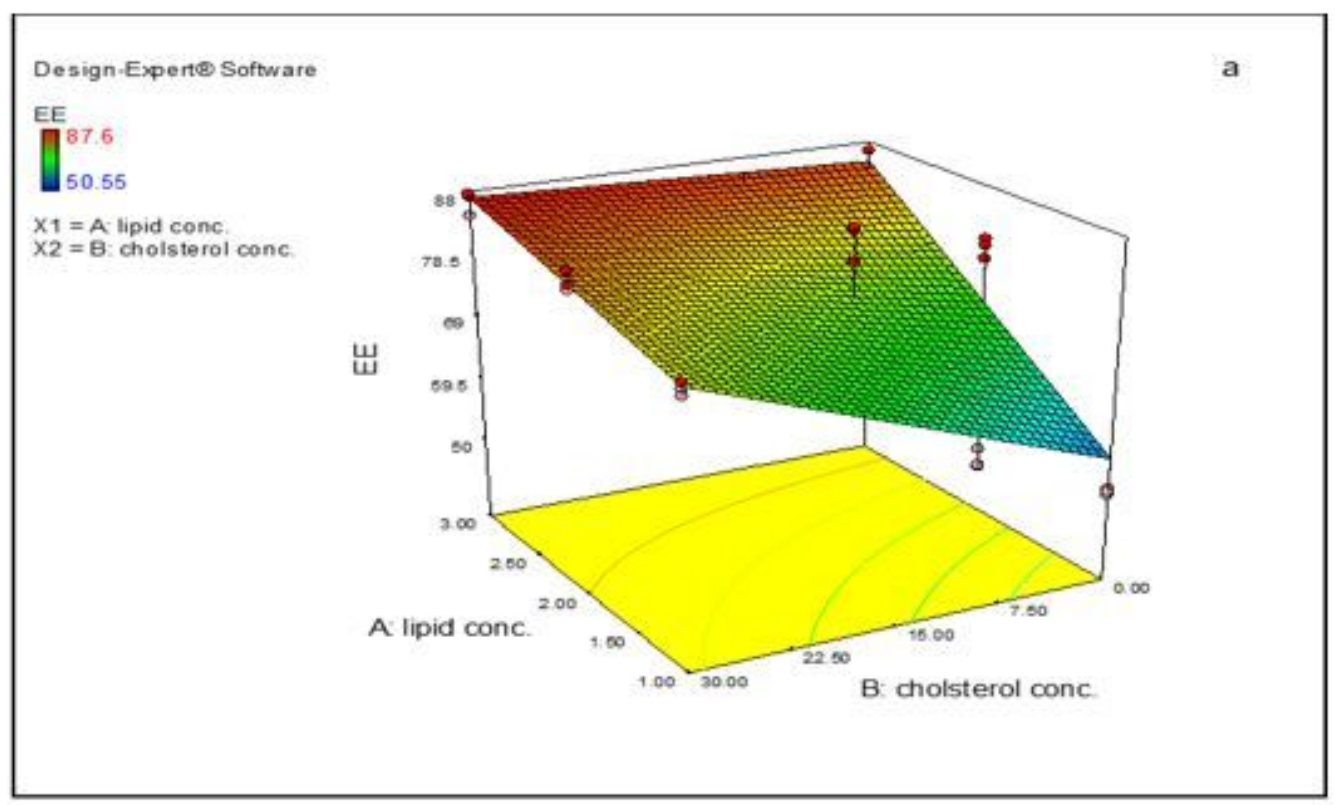

(b)

\section{Figure 1}

3D Surface graph showing the Effect of different formulation variables on PS of bilosomes (a), 3D surface graph showing the effect of different formulation variables on EE of bilosomes (b). 


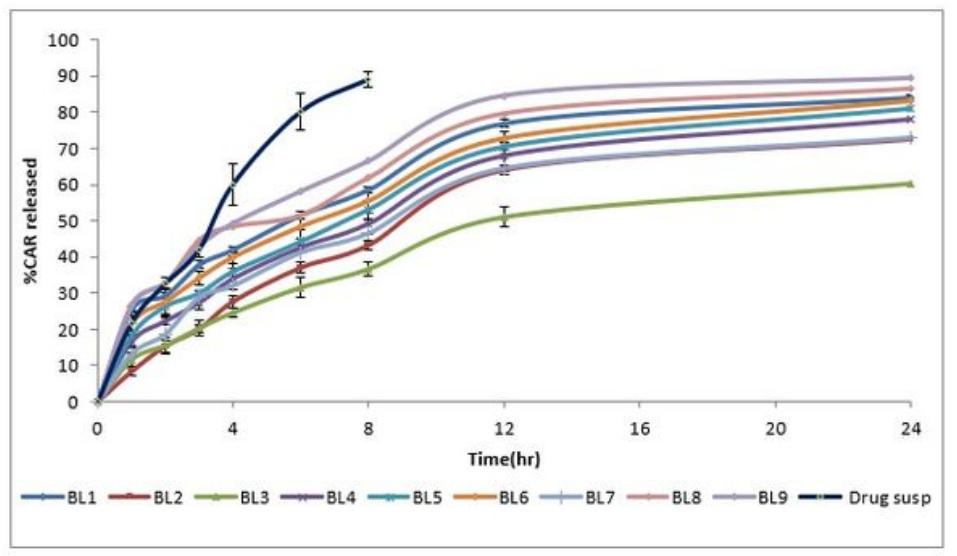

(a)

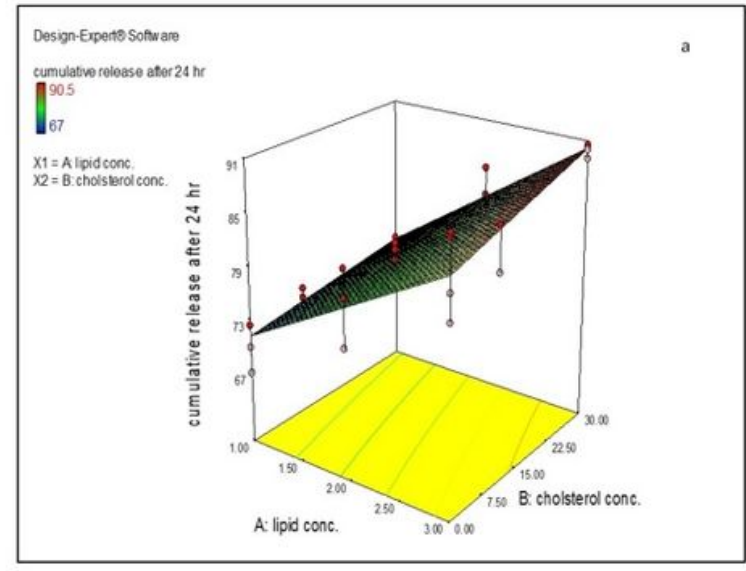

(b)

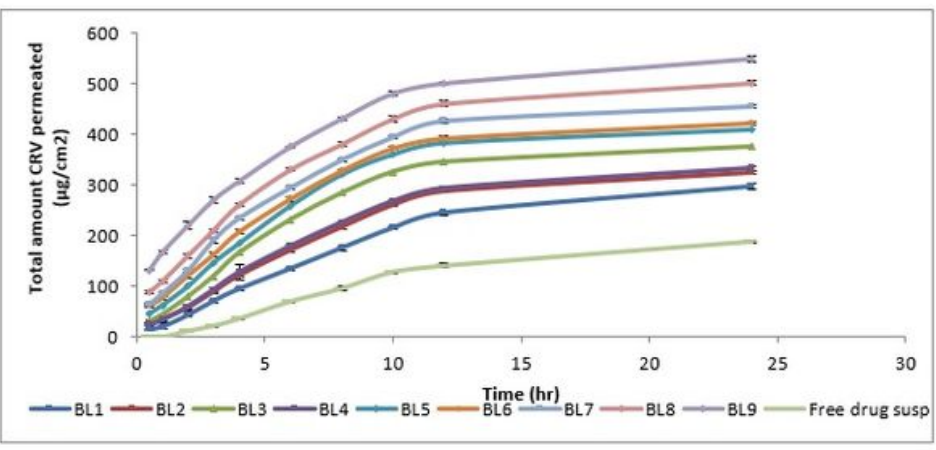

(c)

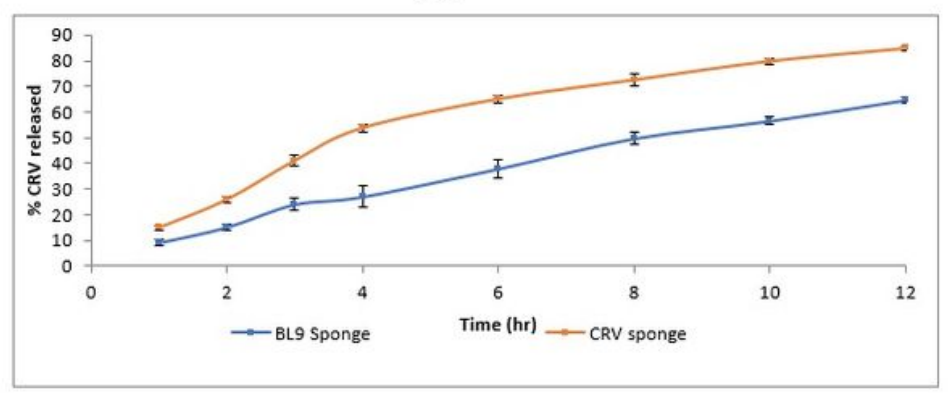

(d)

\section{Figure 2}

Release profile of different bilosome formulae \& CRV Suspension (a), 3D surface plot Effect of different variables on \% CRV released from bilosomes formulae (b), Permeation profiles of the prepared bilosomes formulae \& drug suspension ( $250 \mathrm{~mL}$ phosphate buffer $\mathrm{pH} 6.8,37^{\circ} \mathrm{C}$ and $50 \mathrm{rpm}$ ) (c), Release profile of BL9 loaded sponge and CRV sponge (d). 

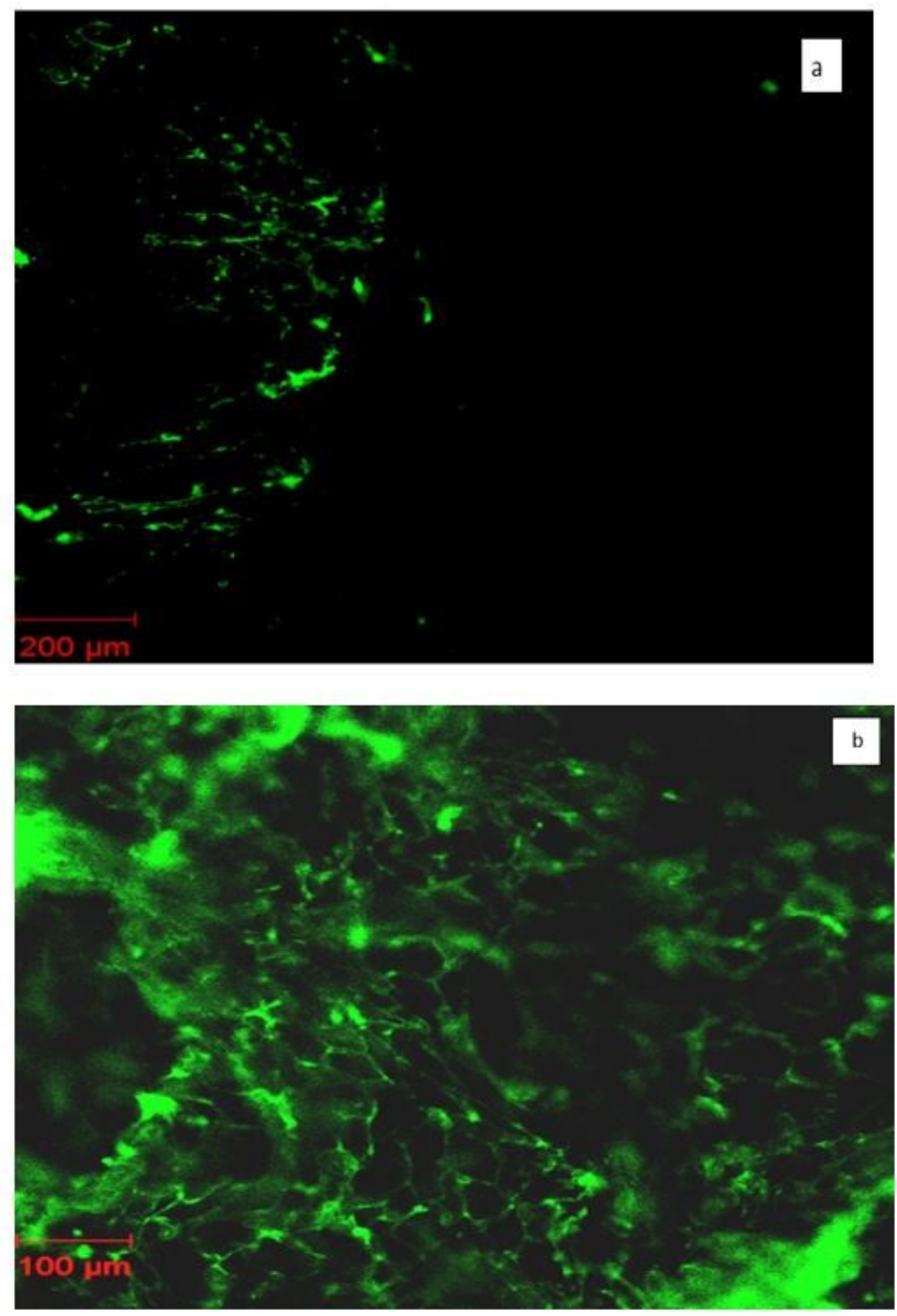

Figure 3

Confocal images of cross-sections of buccal mucosa after application of (a) rhodamine solution and (b) rhodamine-loaded bilosome (BL9). 


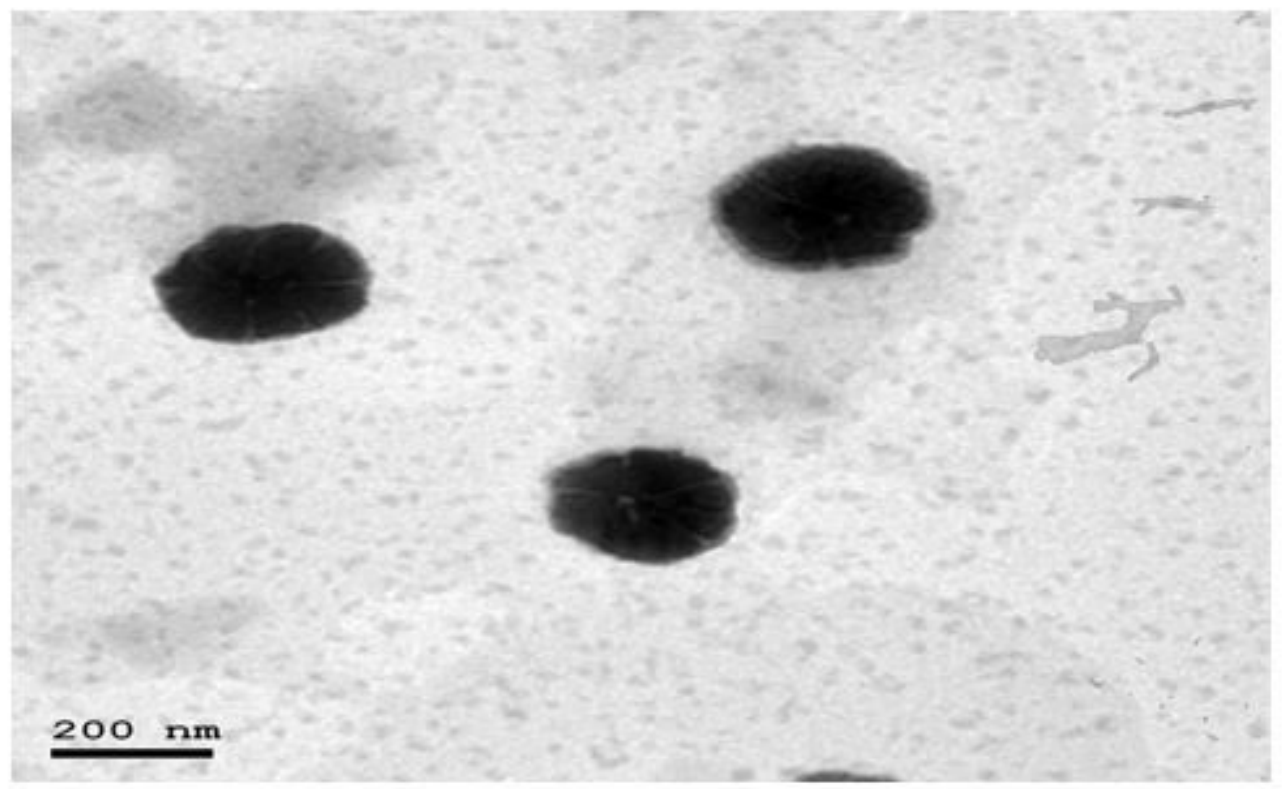

(A)

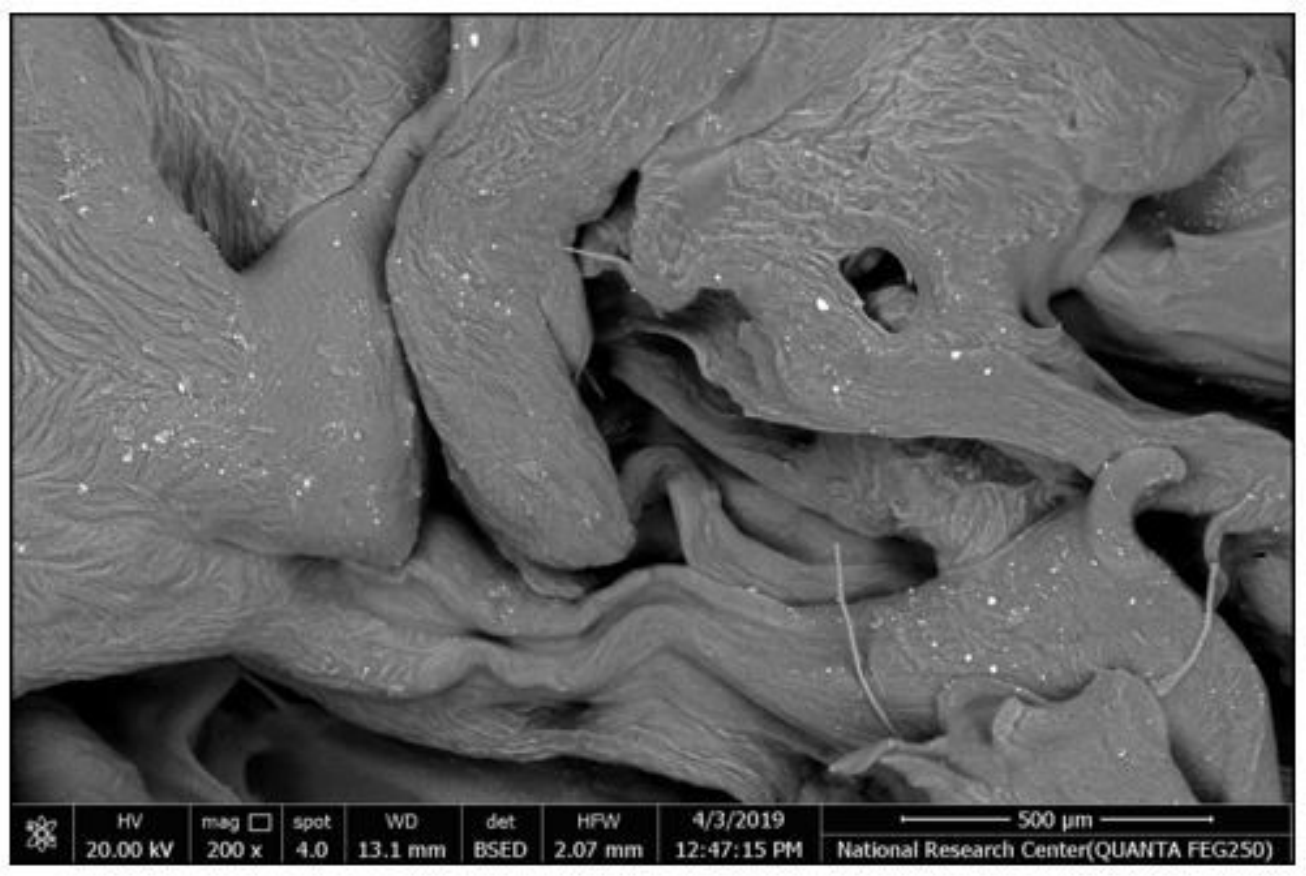

(B)

\section{Figure 4}

Transmission electron micrograph of the optimum bilosomes formula (BL9) (a). SEM micrographs of BL9 loaded sponge (b). 

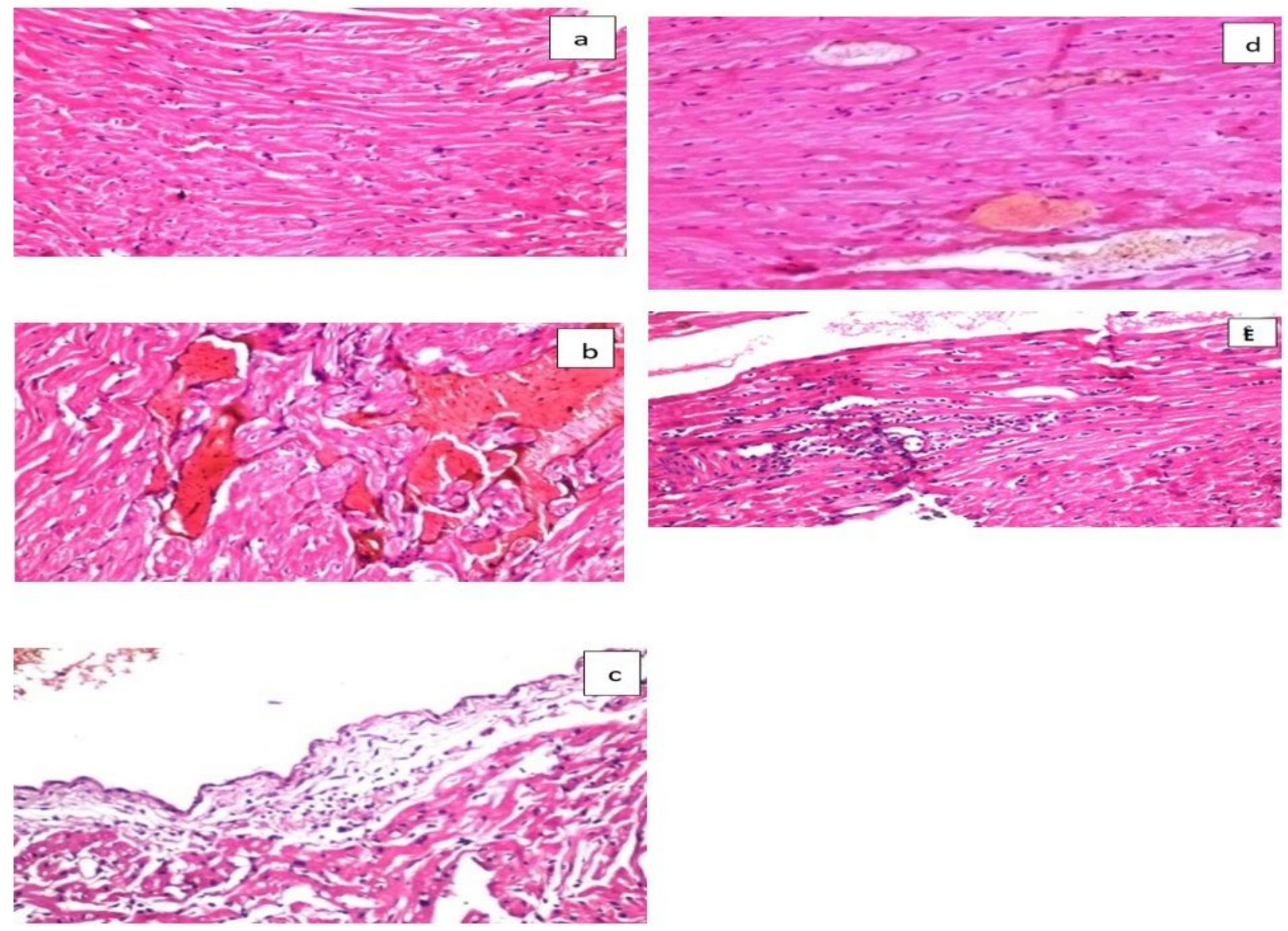

Figure 5

Photomicrographs of $\mathrm{H} \& \mathrm{E}$ stained histological sections of normal rats' heart section (a), $\mathrm{CdCl} 2$ intoxicated rats' heart section (b\&c), Carvid® group rats' heart section (d), BL9 sponge treated rats' heart section (e). 

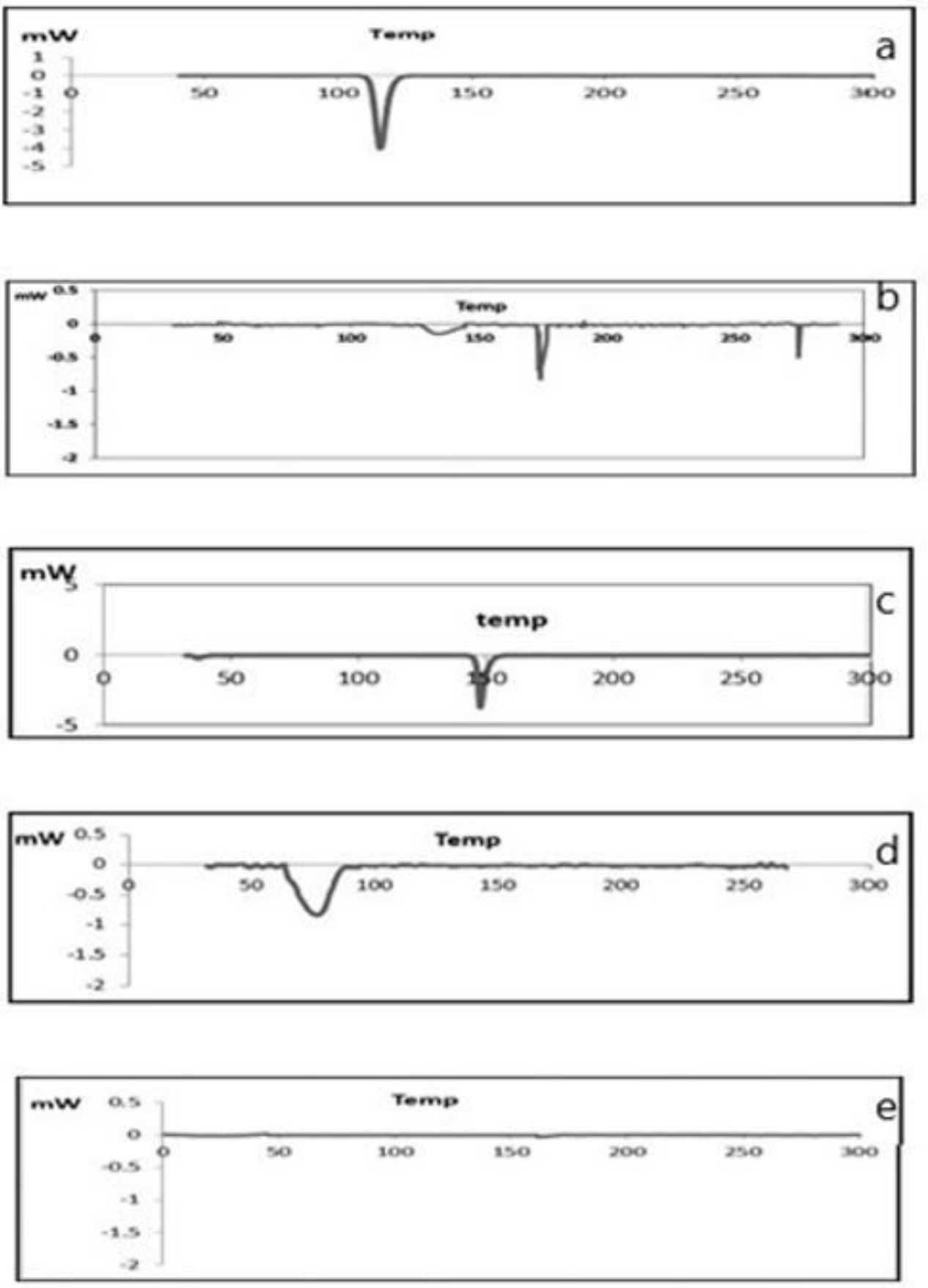

Figure 6

DSC thermograms of pure carvidelol (a), SPC (b), CH (c), SDC(d) and lyophilized optimized bilosomes BL9 formula (e). 


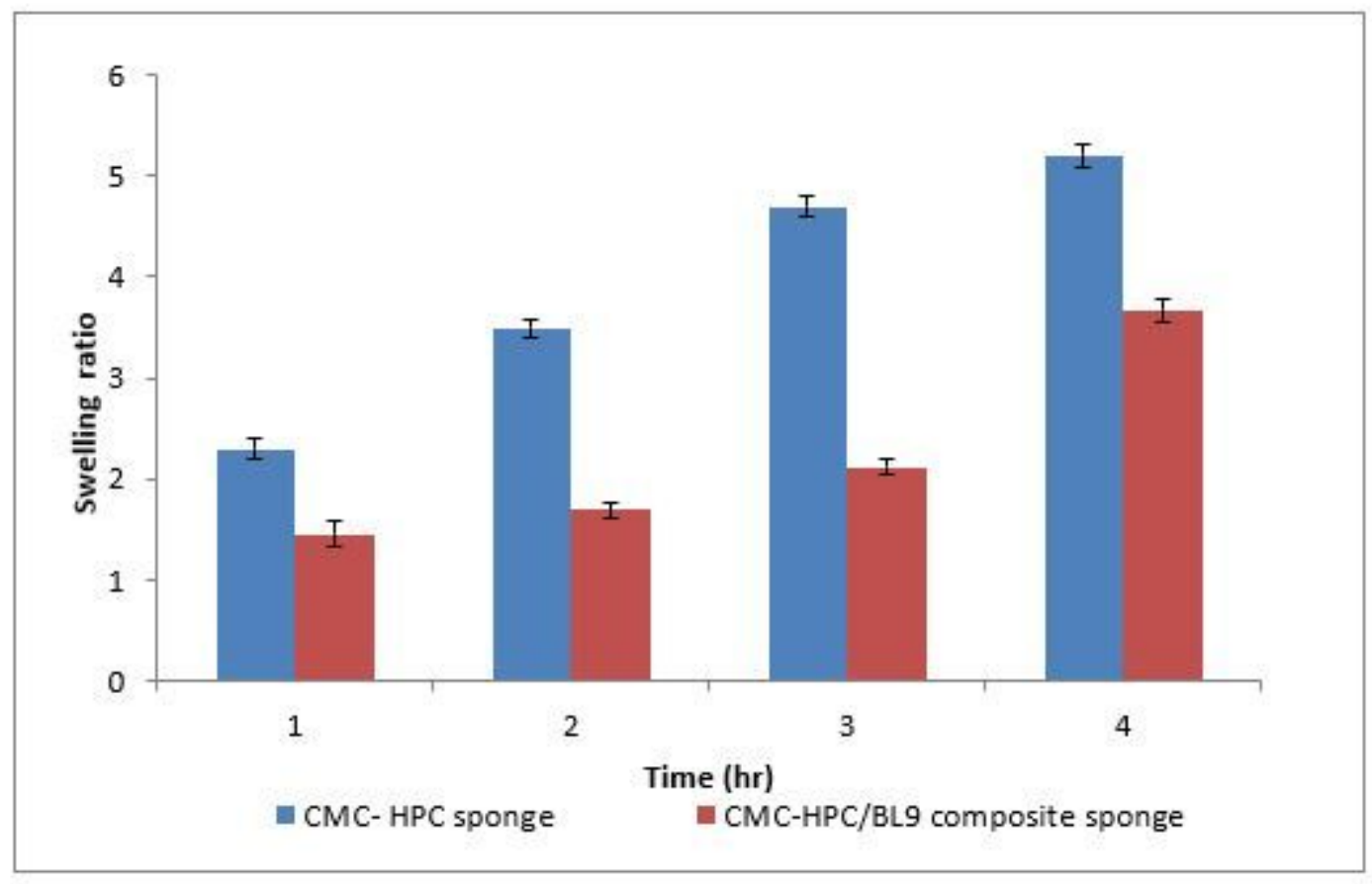

\section{Figure 7}

Swelling of BL9 bilosomes sponge and CRV sponge

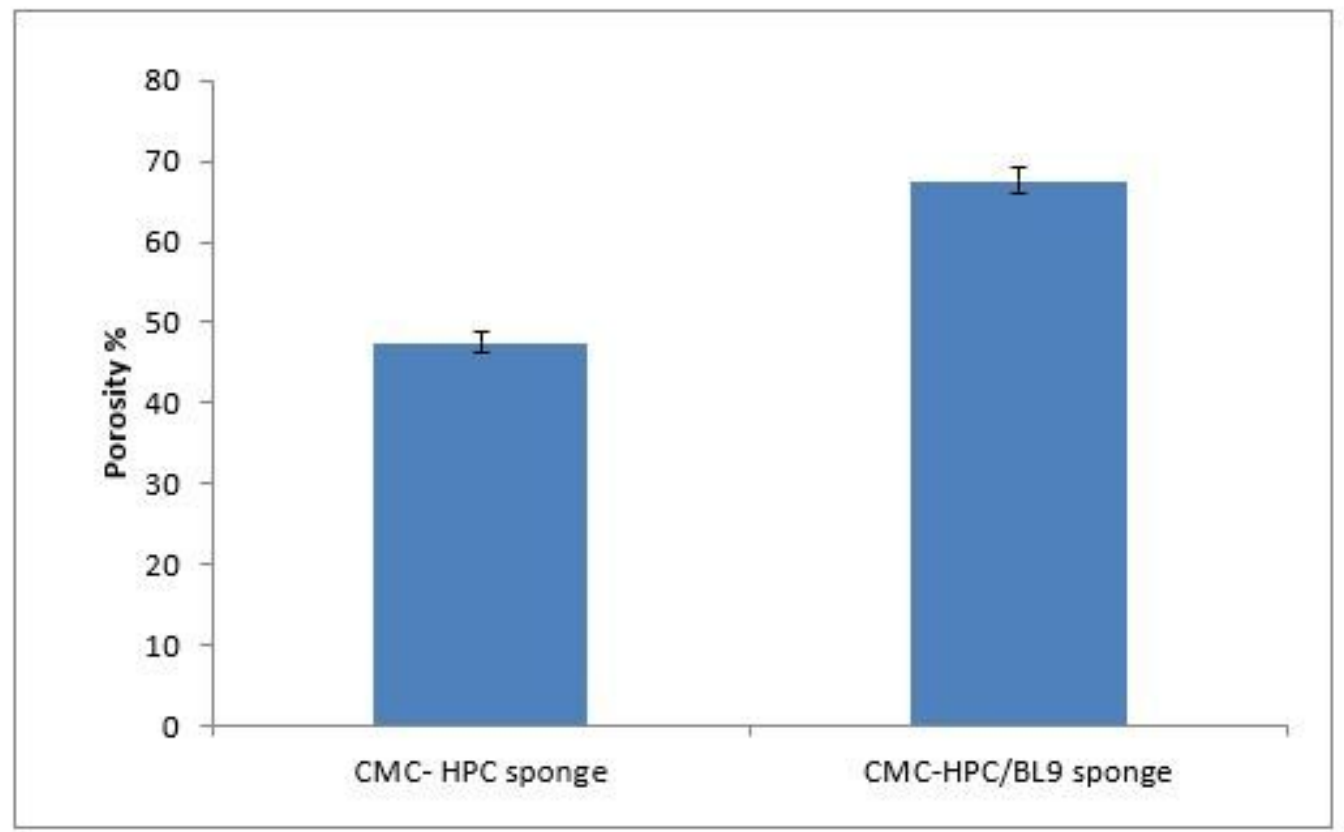

Figure 8

Porosity of BL9 bilosome sponge and CRV sponge 


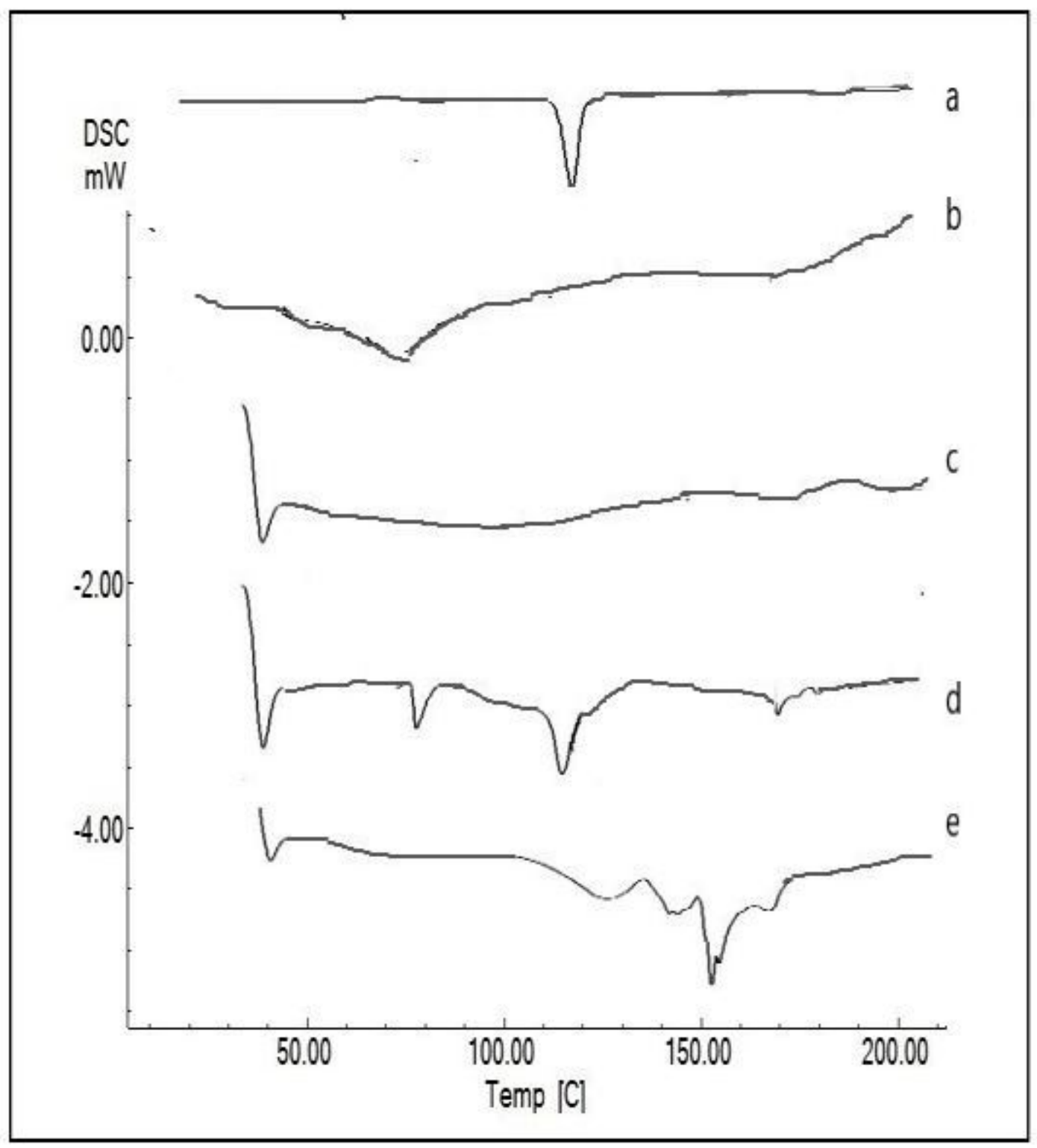

Figure 9

DSC thermograms of pure carvidelol (a), CMC (b), HPC (c), physical mixture (d) and lyophilized bilosomes sponge (e). 

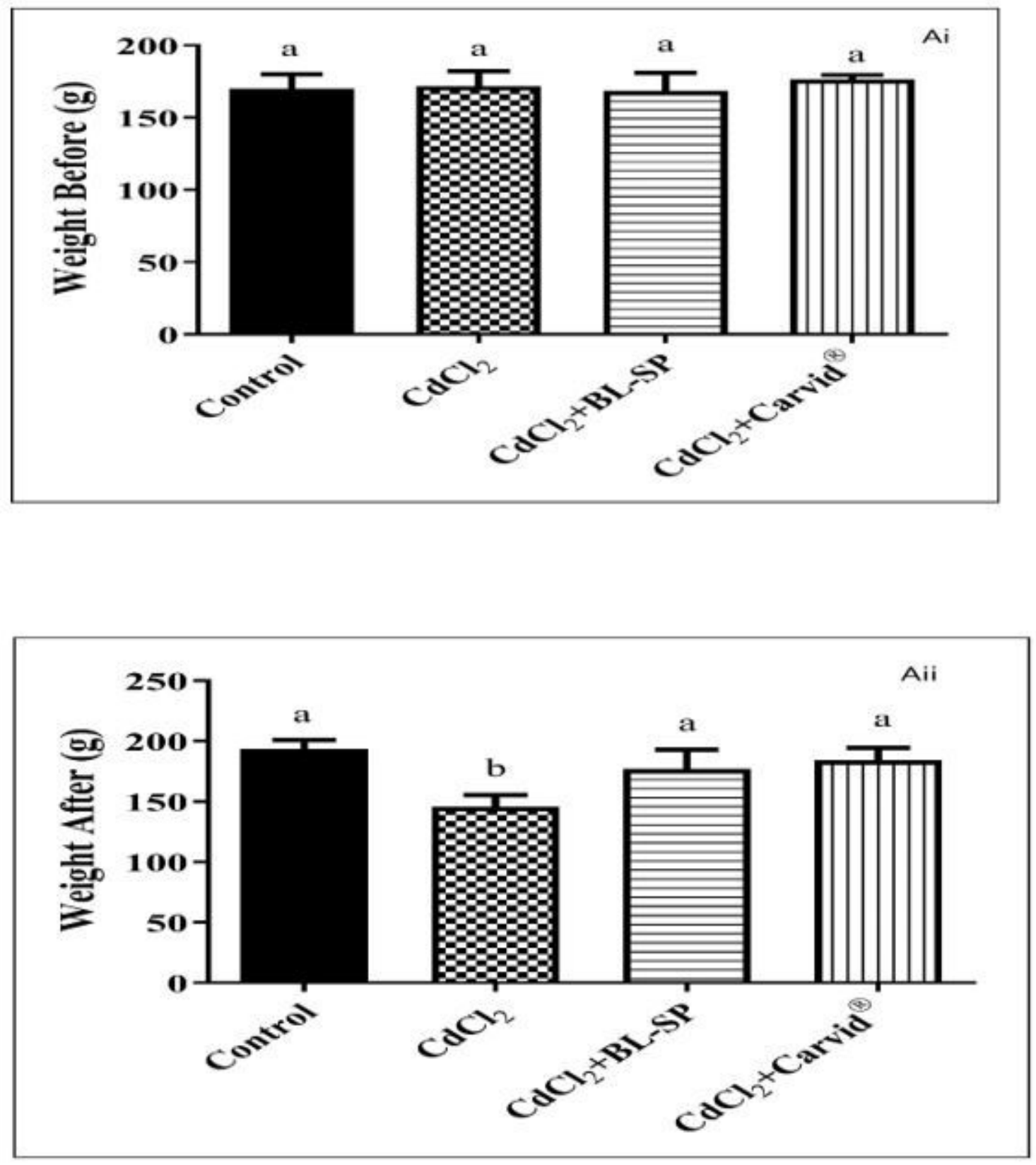

Figure 10

Effect of cadmium exposure and carvedilol bilosomes loaded sponge on body weight (Ai, Aii) (the columns not sharing the same subscript letters were significantly different at $p<0.05$ ). 

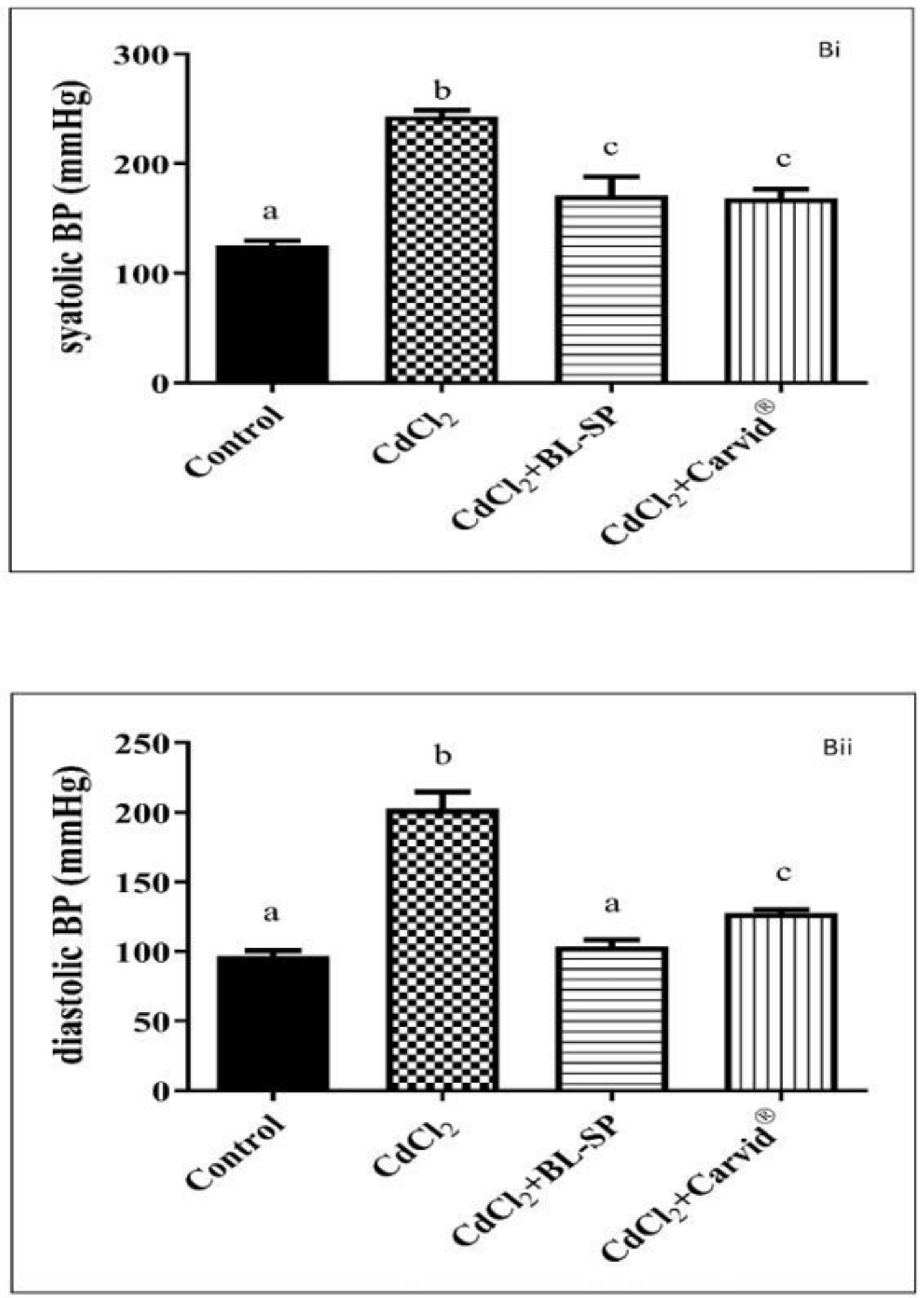

Figure 11

Effect of cadmium exposure and carvedilol bilosomes loaded sponge on blood pressure (Bi, Bii) (the columns not sharing the same subscript letters were significantly different at $p<0.05$ ). 

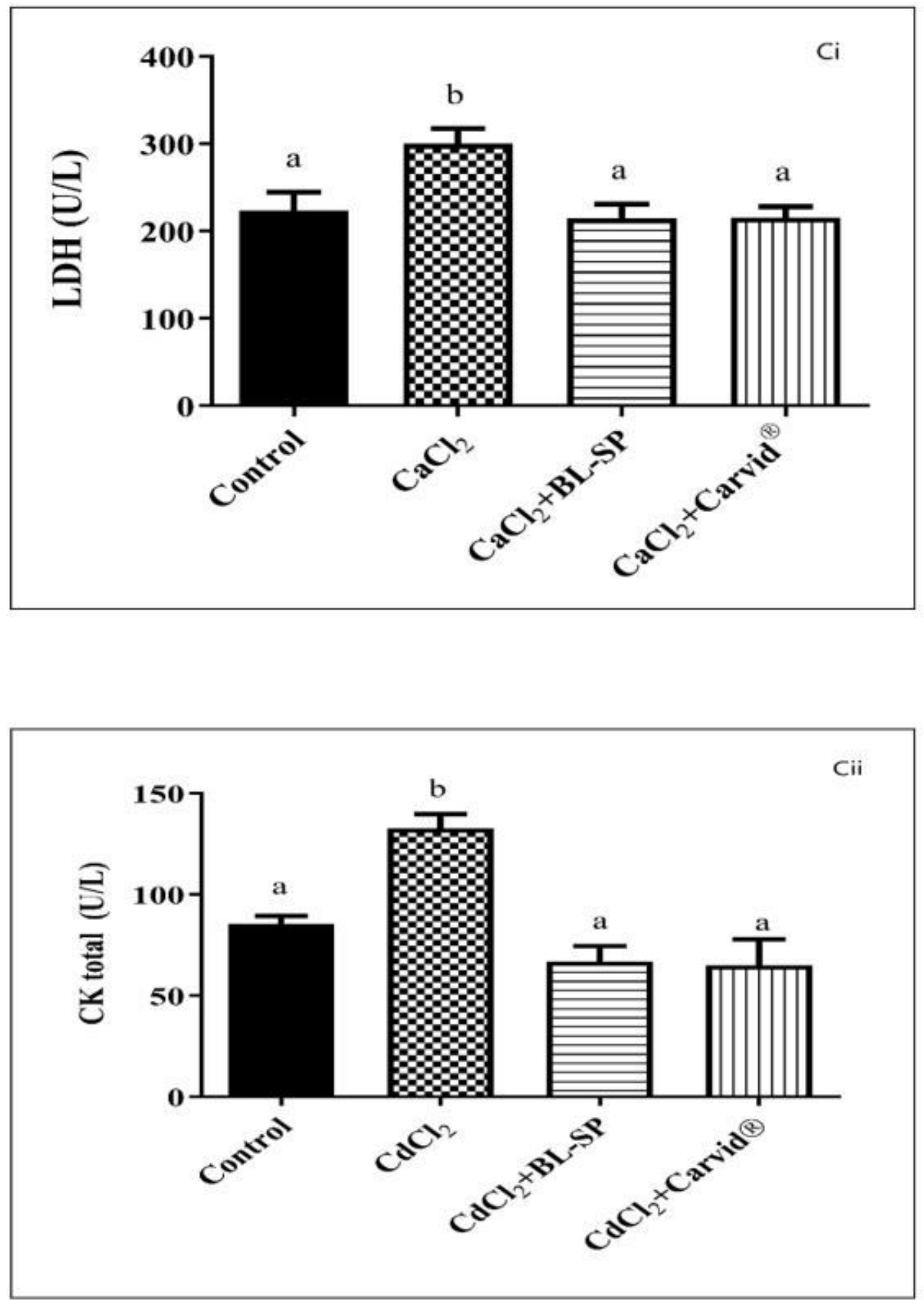

Figure 12

Effect of cadmium exposure and carvedilol bilosomes loaded sponge on Cardiac markers (LDH\& CK) (ci, cii) (the columns not sharing the same subscript letters were significantly different at $p<0.05$ ). 

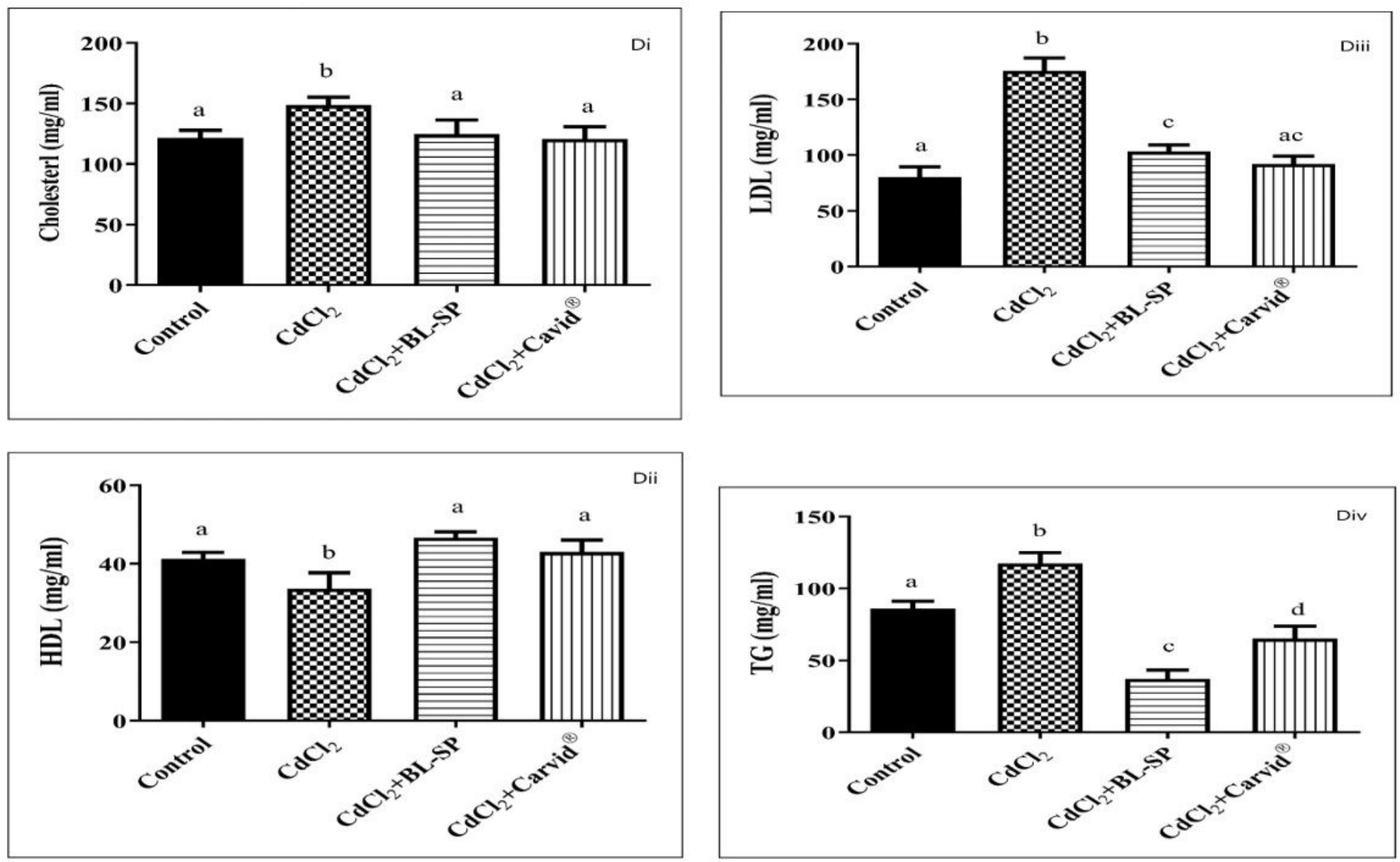

Figure 13

Effect of cadmium exposure and carvedilol and carvedilol bilosomes loaded sponge on serum lipid profile (Di, Dii, Diii, Div) (the columns not sharing the same subscript letters were significantly different at $p<0.05)$. 

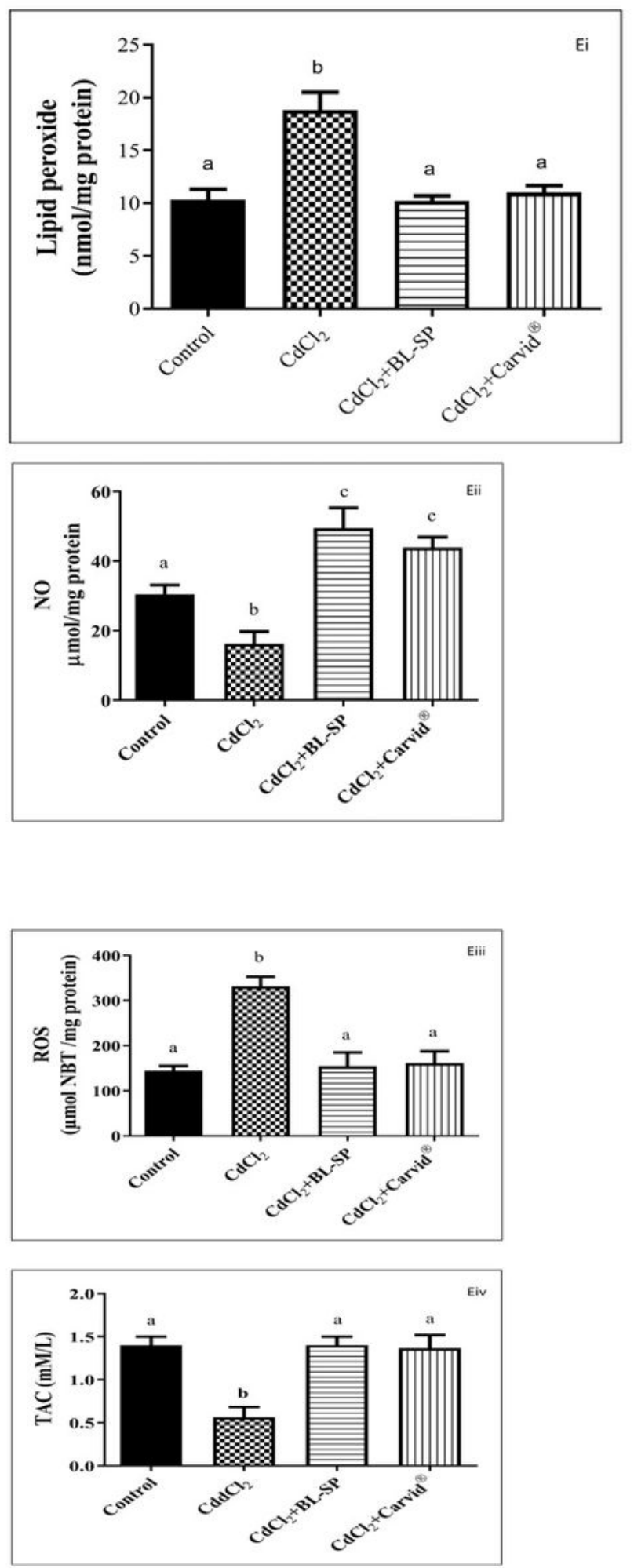

Figure 14

Effect of cadmium exposure and carvedilol and carvedilol bilosomes loaded sponge on oxidative stress markers in heart (LPO, ROS, NO\& TAC) (Ei, Eii, Eiii, Eiv) (the columns not sharing the same subscript letters were significantly different at $p<0.05)$. 